\title{
THE ROLE OF \\ INVESTMENT-SPECIFIC \\ TECHNOLOGY SHOCKS IN \\ DRIVING INTERNATIONAL \\ BUSINESS CYCLES: A BAYESIAN APPROACH
}

\author{
JAYA DEY \\ Saint Louis University
}

This paper uses a Bayesian approach to estimate a standard international real business cycle model augmented with preferences with zero wealth effect, variable capacity utilization, and investment adjustment costs. First, I find that the bulk of fluctuations in country-specific outputs, consumption, investments, and international relative prices can be attributed to country-specific neutral technology, investment-specific technology, and preference shocks. Second, my estimated model with economically meaningful shocks simultaneously accounts for the negative correlation between the real exchange rate and relative consumption and the negative correlation between the terms of trade and relative output. Last, through a marginal likelihood comparison exercise, I find that the success of the model depends on preferences with zero wealth effects; other frictions and alternative asset market structures play a less important role.

Keywords: Bayesian, Investment-Specific Technology, Real Exchange Rate

\section{INTRODUCTION}

Researchers seek to understand the behavior of international quantities and relative prices, such as the real exchange rate and the terms of trade, for their respective welfare and policy implications. First, they seek to understand the sources of the fluctuations of these variables. Second, they also seek to understand the movement of the two relative prices with other real variables. A wealth of literature answers these questions using a variety of different shocks, frictions, and market structures. 
This paper quantitatively evaluates the relative importance of various shocks and rigidities to the international business cycle. I show that my full-information estimated model with complete markets, real rigidities, and technology shocks can explain the dynamics of the quantities and international relative prices. Moreover, my estimated parameters are consistent with the findings of macroeconomists as well as the evidence in the micro data.

I estimate an international real business cycle (IRBC hereafter) model augmented with preferences with zero wealth effects on labor supply, variable capacity utilization, investment adjustment costs, and multiple real shocks, using a Bayesian approach. My estimates establish the importance of country-specific shocks - in particular technology shocks - in accounting for most of the variations in country-specific output, consumption, and investment. In addition, my estimated model accounts for both negative correlation between the real exchange rate and relative consumption, and negative correlation between the terms of trade and relative output. Moreover, although other real shocks play a minor role, I find that investment-specific technology (IST) shocks generate high volatility in open economy variables such as the real exchange rate and terms of trade. Furthermore, using marginal likelihood comparisons, I find that replacing the preferences with zero wealth effect with other commonly used preferences significantly worsens the model fit; in contrast, other frictions are less important.

Standard real business cycle models attribute a dominant role in causing business cycles to neutral technology shocks. In contrast, empirical works such as King et al. (1991), Gali (1999), and Fisher (2006) point out other shocks in explaining the fluctuations in key macroeconomic aggregates. Recently, Smets and Wouters (2007), Justiniano et al. (2010), Ireland (2013), and Jacob and Peersman (2013) systematically evaluate the importance of technology shocks in causing business cycles in closed and open economy settings. ${ }^{1}$ An objective of this paper is to use a system-based approach to evaluate the relative importance of technology shocks in accounting for the observed cross-country comovement in economic fluctuations.

The existing literature points out three major puzzles regarding international relative prices. The first is the real exchange rate puzzle. ${ }^{2}$ The correlation between the real exchange rate and relative consumption is negative in the data; using data on the United States and other OECD countries, it is approximately -0.20 (see Figure 1). However, standard IRBC models typically generate a positive and nearperfect correlation between real exchange rates and cross-country consumption ratios. ${ }^{3}$ Under standard separable preferences (in leisure) and efficient risk sharing, the real exchange rate at equilibrium equals the ratio of marginal utilities of consumption across countries, implying near-perfect correlation between the real exchange rate and relative consumption.

The second puzzle is the terms of trade puzzle. The correlation between the terms of trade and relative output is negative in the data, around -0.29 (see Figure 2). However, IRBC models predict a high positive correlation between the two variables. Under the complete asset markets assumption, the relative scarcity of foreign goods increases after a positive neutral technology shock in the home 


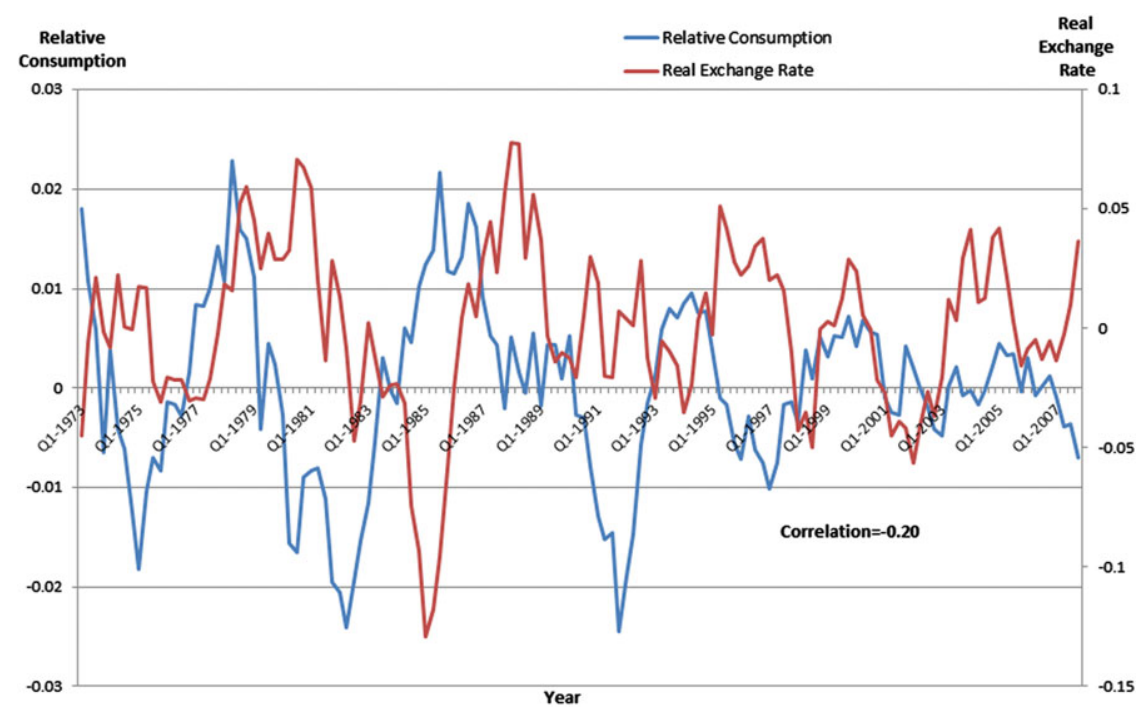

FIGURE 1. Movement in real exchange rate and relative consumption.



FIGURE 2. Movement in terms of trade and relative output. The real exchange rate and terms of trade series are constructed as described in Appendix C. All four series are logged and HP-filtered.

country. Because the value of imports rises relative to the value of exports, the terms of trade depreciate. ${ }^{4}$ In this way, movements in the terms of trade act as insurance against relative changes in productivity across countries.

The third and final puzzle is the twin volatility puzzle. The volatilities of the real exchange rate and terms of trade are found to be very high in the data, around 
9.01 and 6.61, respectively. However, IRBC models typically predict very low volatilities. Such models assume the existence of complete markets, implying high correlation of consumption across countries, and thus low volatility in their ratios. Because households can borrow and lend freely internationally, the relative scarcity effect after a positive productivity shock is small, and this implies low volatility in the terms of trade.

My estimates provide evidence that technology shocks drive between 60 and $99 \%$ of international business cycles. In particular, although neutral and worldneutral technology shocks combined account for between 40 and $70 \%$ of the variance of output and consumption, IST shocks account for more than $90 \%$ of that of investment.

In addition, given my observables and shock processes, my estimated model establishes the importance of the IST shocks in fully resolving the real exchange rate puzzle and the terms of trade puzzle and partly resolving the twin volatility puzzle. Raffo's (2010) study is the first to identify the potential for these shocks to account for the puzzles. After a positive IST shock in the home country, investment becomes relatively cheaper, leading to a strong incentive to accumulate capital. Firms respond by increasing labor input and utilizing existing capital at a higher rate. This further stimulates output and consumption. I assume that household preferences imply zero wealth elasticity of labor supply, as given by Greenwood et al. (1988; GHH hereafter). Under these preferences, the positive substitution effect offsets the negative wealth effect, leading to stronger positive responses of hours to an IST shock. This leads to an appreciation of the real exchange rate, resolving the real exchange rate puzzle. Similarly, increased imports of foreign goods to meet domestic demand offsets the relative scarcity effect, generating an appreciation in terms of trade and hence resolving the terms of trade puzzle. Heathcote and Perri (2013) show that the real exchange rate puzzle can be resolved by introducing preference shocks. My benchmark estimates show that even though preference shocks can resolve the comovement puzzles, they cause negligible movement in the international prices. On the other hand, IST shocks are capable of generating high model-based volatilities in international relative prices, partially resolving the twin volatility puzzle.

Finally, marginal likelihood comparisons under a Bayesian approach show that GHH preferences are a crucial model ingredient; other commonly used frictions and alternative asset market structures are less important. Furthermore, under these preferences, capacity utilization is an important channel for generating the comovement of consumption and output after an IST shock. Also, the presence of capacity utilization allows a stronger response of labor to the shock by increasing the marginal product of labor. As a result, omitting either of these two features significantly hurts the model's predictive power, especially regarding the real exchange rate puzzle.

The role of technology shocks in generating international business cycle fluctuations has attracted the attention of international economists since the seminal work of Backus et al. (1995). Heathcote and Perri (2002) show that under financial 
autarky and neutral technology shocks, a larger rise in international prices is required for markets to clear, inducing higher volatility. Corsetti et al. (2008) introduce incomplete asset markets, accounting for the price puzzles. ${ }^{5}$ Raffo (2010) calibrates an IRBC model with GHH preferences, variable capital utilization, investment adjustment costs, and neutral-technology and IST shocks; this model accounts for the three price puzzles. However, the results rely on calibrated values of exogenous shock processes of IST and neutral-technology shocks, as well as a high Frisch elasticity of labor supply and a low elasticity of substitution between intermediate goods. Another relevant study by Mandelman et al. (2011) finds evidence that both the TFP and IST shock processes in the United States and OECD countries have unit roots and are cointegrated. After incorporating the estimated shocks into their benchmark model, they find that it fails to account for any of the preceding puzzles. Although theoretically, in terms of model ingredients, this paper is closely related to these two studies, empirically it tries to reconcile the opposing results presented in these studies that have employed thoughtful calibration approaches.

The approach of identification of IST shocks using relative prices is commonly used in closed economy studies. ${ }^{6}$ However, Basu and Thoenissen (2011) show that in an open economy framework, the relative price of investment may not be adequate to capture all investment frictions. They demonstrate that other than IST shocks, the relative price of investment is also affected by movements in terms of trade and relative degree of home bias in consumption and investment goods sectors. Furthermore, Jacob and Peersman (2013) find that their identified shocks to the relative price of investment and the marginal efficiency of investment have opposing effects on relative price series. Whereas the shocks to the relative price of investment have a negative impact on the series, the shocks to the marginal efficiency of investment have a positive impact. For all these reasons, I do not include observations on the relative price of investment to identify IST shocks in my benchmark model. In this way, I allow the IST shocks to capture all other sources of variation in marginal efficiency of investment goods apart from the one attributed to the variability of relative price of investment. $^{7}$

This paper is also related to the growing literature on the estimation of dynamic stochastic general equilibrium models in an open economy setting using Bayesian techniques. Adolfson et al. (2007) estimate a fully articulated small open economy model using data from the Euro area. Rabanal and Tuesta (2010) estimate an open economy model with alternative market structures and frictions and find that the model with local currency pricing and incomplete markets has a better fit overall than a model with neither of the two features. Lubik and Schorfheide (2006) estimate an open economy model to examine the propagation of monetary policy shocks and exchange rate dynamics. ${ }^{8}$ By using a more parsimonious model than these studies, this paper undertakes a quantitative evaluation of the relative potential for real shocks and rigidities in accounting for international business cycles. 
The rest of the paper is organized as follows. I present my IRBC model in Section 2 and the estimation methodology along with priors in Section 3. Section 4 reports the forecast error variance decomposition and analyzes the results. Section 5 studies model sensitivity, and Section 6 concludes the paper.

\section{MODEL}

\subsection{Preferences and Technology}

My model is based on the framework developed in Heathcote and Perri (2002) and Raffo (2010). The trade structure is such that each country $i(=\mathrm{H}, \mathrm{F})$ specializes in the production of one intermediate $\operatorname{good}(j=a, b)$. Specifically, intermediate goods firms in the home country $\mathrm{H}$ produce $a$ and firms in the foreign country F produce $b$. Let $W_{i}\left(s^{t}\right)$ and $R_{i}\left(s^{t}\right)$ be the wage and the rental rate on capital in country $i$ in terms of final goods units. ${ }^{9}$ The intermediate goods producers in country $i$ solve the standard profit maximization problem,

$$
\begin{aligned}
& \operatorname{Max}_{K_{i}\left(s^{t}\right) \geq 0, L_{i}\left(s^{t}\right) \geq 0} F\left(z_{i}\left(s^{t}\right), K_{i}\left(s^{t}\right), h_{i}\left(s^{t}\right), A\left(s^{t}\right), l_{i}\left(s^{t}\right)\right)-W_{i}\left(s^{t}\right) l_{i}\left(s^{t}\right) \\
& \quad-R_{i}\left(s^{t}\right) K_{i}\left(s^{t}\right) h_{i}\left(s^{t}\right),
\end{aligned}
$$

subject to

$$
F\left(z_{i}\left(s^{t}\right), K_{i}\left(s^{t}\right), h_{i}\left(s^{t}\right), A\left(s^{t}\right), l_{i}\left(s^{t}\right)\right)=z_{i}\left(s^{t}\right) A\left(s^{t}\right)\left(K_{i}\left(s^{t}\right) h_{i}\left(s^{t}\right)\right)^{\alpha}\left(l_{i}\left(s^{t}\right)\right)^{(1-\alpha)},
$$

where $h_{i}\left(s^{t}\right)$ and $l_{i}\left(s^{t}\right)$ denote the variable capacity utilization and the hours worked after history $s^{t}$. The amount of capital services supplied is $h_{i}\left(s^{t}\right) K_{i}\left(s^{t}\right)$ in period $t$. $A\left(s^{t}\right)$ denotes a world neutral-technology shock that follows a unit root process with a drift:

$$
\log \left(A\left(s^{t}\right)\right)=\Gamma_{a}+\log \left(A\left(s^{(t-1)}\right)\right)+\epsilon^{a}\left(s^{t}\right),
$$

where $\epsilon^{a}\left(s^{t}\right)$ follows a zero-mean I.I.D. normal with a standard deviation of $\sigma^{a}$. The country-specific neutral-technology shock $z_{i}\left(s^{t}\right)$ has the law of motion

$$
\log \left(z_{i}\left(s^{t}\right)\right)=\rho_{i}^{z} \log \left(z_{i}\left(s^{t-1}\right)\right)+\epsilon_{i}^{z}\left(s^{t}\right),
$$

where $\epsilon_{i}^{z}\left(s^{t}\right)$ is a zero-mean I.I.D. normal with a standard deviation of $\sigma_{i}^{z}$.

After intermediate goods have been produced, households trade them in the frictionless international spot market. I assume that the law of one price holds throughout. After trading in the international market, the households sell all their holdings of intermediate goods to domestic final goods firms. The final goods produced can either be consumed or be invested. The intermediate goods are combined in each country to produce the final goods using an Armington aggregator. The final goods problem in country $i$ is given by

$$
\operatorname{Max}_{a_{i}\left(s^{t}\right), b_{i}\left(s^{t}\right) \geq 0} G_{i}\left(a_{i}\left(s^{t}\right), b_{i}\left(s^{t}\right)\right)-q_{i}^{a}\left(s^{t}\right) a_{i}\left(s^{t}\right)-q_{i}^{b}\left(s^{t}\right) b_{i}\left(s^{t}\right),
$$


subject to

$$
G_{i}\left(a_{i}\left(s^{t}\right), b_{i}\left(s^{t}\right)\right)= \begin{cases}{\left[\omega a_{i}\left(s^{t}\right)^{\frac{\theta-1}{\theta}}+(1-\omega) b_{i}\left(s^{t}\right)^{\frac{\theta-1}{\theta}}\right]^{\frac{\theta}{\theta-1}},} & i=\mathrm{H}, \\ {\left[(1-\omega) a_{i}\left(s^{t}\right)^{\frac{\theta-1}{\theta}}+\omega b_{i}\left(s^{t}\right)^{\frac{\theta-1}{\theta}}\right]^{\frac{\theta}{\theta-1}},} & i=\mathrm{F},\end{cases}
$$

where $\theta$ denotes the elasticity of substitution between intermediate goods $a$ and $b$, and $\omega>0.5$ determines the home bias in the composition of domestically produced final goods. ${ }^{10} q_{i}^{a}\left(s^{t}\right)$ and $q_{i}^{b}\left(s^{t}\right)$ are the prices of goods $a$ and $b$ in country $i$ in units of the final goods produced in country $i$.

The agents maximize their lifetime utility $(U)$ defined over sequences of consumption $C_{i}\left(s^{t}\right)$ and hours worked $l_{i}\left(s^{t}\right)$. At any point in time, the amount of labor and leisure should add up to the period endowment of time, which is normalized to 1 . The household preferences are

$$
U\left(C_{i}\left(s^{t}\right), 1-l_{i}\left(s^{t}\right)\right)=g_{i}\left(s^{t}\right)\left[\frac{\left[\left(C_{i}\left(s^{t}\right)-Z\left(s^{t-1}\right) \psi l_{i}\left(s^{t}\right)^{\tau}\right)^{\left(1-\sigma_{c}\right)}\right]-1}{\left(1-\sigma_{c}\right)}\right]
$$

where $g_{i}$ is the preference shock for country $i$, which has the following law of motion:

$$
\log \left(g_{i}\left(s^{t}\right)\right)=\rho_{i}^{g} \log \left(g_{i}\left(s^{t-1}\right)\right)+\epsilon_{i}^{g}\left(s^{t}\right)
$$

where $\epsilon_{i}^{g}\left(s^{t}\right)$ is zero-mean I.I.D. normal with a standard deviation of $\sigma_{i}^{g}$. Following Mandelman et al. (2011), the preferences are augmented with a composite nonstationary world technology shock $Z\left(s^{t-1}\right)$ (to be described later) to obtain a formulation that is consistent with balanced growth. The households supply labor and rent capital to firms producing intermediate goods in a perfectly competitive market. The Frisch elasticity of the labor supply is given as $\frac{1}{\tau-1}$. Both the factors of production are internationally immobile, and households in each country own the capital stock of that country.

There is a complete set of Arrow securities, denominated in units of good $a$. Let $B_{i}\left(s^{t}, s_{t+1}\right)$ be the quantity of bonds purchased by households in country $i$ that pay one unit of good $a$ in period $t+1$ if and only if the state of the economy is $s_{t+1}$. Let $Q\left(s^{t}, s_{t+1}\right)$ be the price of these bonds in units of good $a$. Under complete markets, the budget constraint of a representative household in country $\mathrm{H}$ is

$$
\begin{aligned}
& q_{\mathrm{H}}^{a}\left(s^{t}\right)\left(W_{\mathrm{H}}\left(s^{t}\right) l_{\mathrm{H}}\left(s^{t}\right)+r_{\mathrm{H}}\left(s^{t}\right) h_{\mathrm{H}}\left(s^{t}\right) K_{\mathrm{H}}\left(s^{t}\right)\right)+q_{\mathrm{H}}^{a}\left(s^{t}\right) B_{\mathrm{H}}\left(s^{t-1}, s_{t}\right) \\
& \quad=C_{\mathrm{H}}\left(s^{t}\right)+I_{\mathrm{H}}\left(s^{t}\right)+q_{\mathrm{H}}^{a}\left(s^{t}\right) \sum_{s_{t+1}} Q\left(s^{t}, s_{t+1}\right) B_{\mathrm{H}}\left(s^{t}, s_{t+1}\right) .
\end{aligned}
$$

The budget constraint in country $\mathrm{F}$ is analogous to the preceding constraint. Capital follows the standard law of motion of Christiano et al. (2005) and Mandelman 
et al. (2011)-type convex investment adjustment costs,

$$
\begin{aligned}
& K_{i}\left(s^{t}\right)=\left(1-\delta\left(h_{i}\left(s^{t}\right)\right)\right) K_{i}\left(s^{t}\right) \\
& \quad+v_{i}\left(s^{t}\right) V\left(s^{t}\right)\left[I_{i}\left(s^{t}\right)-\frac{\phi}{2} I_{i}\left(s^{t-1}\right) \frac{V\left(s^{t-1}\right)}{V\left(s^{t}\right)}\left(\frac{I_{i}\left(s^{t}\right) V\left(s^{t}\right)}{I_{i}\left(s^{t-1}\right) V\left(s^{t-1}\right)}-\Lambda_{x}\right)^{2}\right],
\end{aligned}
$$

where $\delta$ is the rate of depreciation of old capital and $I_{i}\left(s^{t}\right)$ is the investment in country $i$. The households can increase the revenue from rental services of capital either by investing in additional capital that can be used in the next period or by increasing the utilization rate of existing capital. A higher utilization rate, however, causes faster depreciation of capital. The depreciation rate $\delta\left(h_{i}\left(s^{t}\right)\right)$ is an increasing convex function of the utilization rate. Specifically, I assume the functional form given in $\mathrm{GHH}$ :

$$
\delta\left(h_{i}\left(s^{t}\right)\right)=\kappa \frac{h_{i}\left(s^{t}\right)^{\sigma_{u}+1}}{\sigma_{u}+1} .
$$

$V\left(s^{t}\right)$ denotes a world IST shock that follows a unit root process with a drift:

$$
\log \left(V\left(s^{t}\right)\right)=\Gamma_{v}+\log \left(V\left(s^{(t-1)}\right)\right)+\epsilon^{v}\left(s^{t}\right),
$$

where $\epsilon^{v}\left(s^{t}\right)$ follows a zero-mean I.I.D. normal with a standard deviation of $\sigma^{v}$. There are two reasons for introducing this shock into the model. First, because my model is matched to eight time series variables but has only seven structural shocks, it runs into the problem of stochastic singularity, a situation that arises when there are fewer stochastic disturbances than observables. Inclusion of this shock helps restore nonsingularity. ${ }^{11}$ Second, similarly to the world neutral-technology shock, a world IST shock captures the cross-country correlations and spillover effects of country-specific IST shocks, which are otherwise assumed to be orthogonal to each other.

Here $v_{i}\left(s^{t}\right)$ denotes the country-specific IST shock and has the following law of motion:

$$
\log \left(v_{i}\left(s^{t}\right)\right)=\rho_{i}^{v} \log \left(v_{i}\left(s^{t-1}\right)\right)+\epsilon_{i}^{v}\left(s^{t}\right),
$$

where $\epsilon_{i}^{v}\left(s^{t}\right)$ is a zero-mean I.I.D. normal with a standard deviation of $\sigma_{i}^{v}$. Using a multisector model, Justiniano et al. (2011) show that $v_{i}\left(s^{t}\right)$ can be further decomposed into two kinds of investment shocks with distinct structural origins: a shock to the relative price of investment and a shock to the marginal efficiency of investment. On one hand, the former affects the transformation of consumption goods into investment goods and can be directly identified using the observations on the relative price of investment. On the other hand, the latter affects the transformation of investment goods into newly produced capital goods and can be identified through the restrictions implied by the optimality conditions in the general equilibrium model. The shock to the marginal efficiency of investment can also be interpreted as a wedge capturing any source of variations in the marginal 
efficiency of investment that can be attributed to other financial factors and financial frictions. ${ }^{12}$ Finally, Justiniano et al. (2011) suggest that although shocks to the marginal efficiency of investment cause most of the output, hours, and investment fluctuations in the United States, shocks to the relative price of investment make a negligible contribution. Jacob and Peersman (2013) obtain similar results for U.S. trade balances. I will treat the two disturbances as a unique shock [e.g., Smets and Wouters (2003, 2007); Justiniano et al. (2010); and Rabanal and Tuesta (2010)], which I will identify using cross-country investment quantity data series. Hence the IST shock in this study is not restricted to the technology innovation specific to investment goods, but has a broader interpretation as a combined shock capturing all disturbances to investment and capital accumulation.

The household in each country maximizes utility $(U)$ subject to the budget constraint and the law of motion of capital, taking as given initial productivity shocks, capital stocks, prices, and the distribution of bonds.

\subsection{Equilibrium}

An equilibrium is an allocation and a set of prices for all $s^{t}$ and for all $t \geq 0$ such that, at given prices, all agents and both types of firms optimize and markets clear. Market clearing for final goods requires that

$$
C_{i}\left(s^{t}\right)+I_{i}\left(s^{t}\right)=G_{i}\left(a_{i}\left(s^{t}\right), b_{i}\left(s^{t}\right)\right), i=\mathrm{H}, \mathrm{F} .
$$

Market clearing for intermediate goods requires that

$$
\begin{gathered}
a_{\mathrm{H}}\left(s^{t}\right)+a_{\mathrm{F}}\left(s^{t}\right)=F\left(z_{\mathrm{H}}\left(s^{t}\right), A\left(s^{t}\right), K_{\mathrm{H}}\left(s^{t}\right), h_{\mathrm{H}}\left(s^{t}\right), l_{\mathrm{H}}\left(s^{t}\right)\right), \\
b_{\mathrm{H}}\left(s^{t}\right)+b_{\mathrm{F}}\left(s^{t}\right)=F\left(z_{\mathrm{F}}\left(s^{t}\right), A\left(s^{t}\right), K_{\mathrm{F}}\left(s^{t}\right), h_{\mathrm{F}}\left(s^{t}\right), l_{\mathrm{F}}\left(s^{t}\right)\right) .
\end{gathered}
$$

Finally, bond market clearing requires that

$$
B_{\mathrm{H}}\left(s^{t}, s_{t+1}\right)+B_{\mathrm{F}}\left(s^{t}, s_{t+1}\right)=0, \forall s_{t+1} \in S
$$

\subsection{Additional Variables}

The following variables will be the focus of my analysis, along with the variables determined by the model. Gross domestic product in country $i$ in units of the final consumption good is

$$
\operatorname{gdp}_{i}\left(s^{t}\right)=q_{i}^{a}\left(s^{t}\right) F\left(z_{i}\left(s^{t}\right), A\left(s^{t}\right), K_{i}\left(s^{t}\right), h_{i}\left(s^{t}\right), l_{i}\left(s^{t}\right)\right) .
$$

The net exports for country $H$ as a fraction of GDP for country $H$ are

$$
\mathrm{nx}\left(s^{t}\right)=\frac{q_{\mathrm{H}}^{a}\left(s^{t}\right) a_{\mathrm{F}}\left(s^{t}\right)-q_{\mathrm{H}}^{b}\left(s^{t}\right) b_{\mathrm{H}}\left(s^{t}\right)}{\operatorname{gdp}_{\mathrm{H}}\left(s^{t}\right)} .
$$


The terms of trade are defined as the price of imports relative to exports:

$$
\operatorname{tot}\left(s^{t}\right)=\frac{q_{i}^{b}\left(s^{t}\right)}{q_{i}^{a}\left(s^{t}\right)}, i=\mathrm{H}, \mathrm{F} .
$$

Let $\operatorname{rer}\left(s^{t}\right)$ be the real exchange rate, defined as the price of consumption in country 2 relative to consumption in country 1 . Applying the law of one price to intermediate goods implies that

$$
\operatorname{rer}\left(s^{t}\right)=\frac{q_{\mathrm{H}}^{a}\left(s^{t}\right)}{q_{\mathrm{F}}^{a}\left(s^{t}\right)}=\frac{q_{\mathrm{H}}^{b}\left(s^{t}\right)}{q_{\mathrm{F}}^{b}\left(s^{t}\right)} .
$$

\subsection{Optimality Conditions}

In the presence of unit root world technology shock processes, my model is nonstationary and does not have a unique steady state. To render the model stationary, I detrend the level of output, consumption, investment, and wages by the productivity level $Z_{t-1}$ and level of capital $K_{t-1}$ by $Z_{t-1} V_{t-1}$, where $Z_{t-1}=A_{t-1}^{1 /(1-\alpha)} V_{t-1}^{\alpha /(1-\alpha)}$. The transformed stationary variables are denoted by lower case characters, for example, $x_{t}=X_{t} / Z_{t-1}$. Let $\Lambda_{\mathrm{H}}^{1}$ and $\Lambda_{\mathrm{H}}^{2}$ be Lagrangian multipliers for constraints (2.6) and (2.7), respectively. The first-order conditions from the households' problem in country $\mathrm{H}$, after the variables are detrended, are ${ }^{13}$

$$
\begin{gathered}
{\left[c_{\mathrm{H}, t}\right]: \frac{g_{\mathrm{H}, t}}{\left(c_{\mathrm{H}, t}-\psi l_{\mathrm{H}, t}^{\tau}\right)^{\sigma_{c}}}=\Lambda_{\mathrm{H}, t}^{1},} \\
{\left[l_{\mathrm{H}, t}\right]: \frac{g_{\mathrm{H}, t}}{\left(c_{\mathrm{H}, t}-\psi l_{\mathrm{H}, t}^{\tau}\right)^{\sigma_{c}}} \psi \tau l_{\mathrm{H}, t}^{\tau-1}=\Lambda_{\mathrm{H}, t}^{1} w_{\mathrm{H}, t} q_{\mathrm{H}, t}^{a},}
\end{gathered}
$$

$$
\begin{aligned}
& {\left[k_{\mathrm{H}, t+1}\right]: g_{Z t}^{\sigma_{c}} g_{V t} \Lambda_{\mathrm{H}, t}^{2}} \\
& =\beta E_{t}\left[\Lambda_{\mathrm{H}, t+1}^{1} q_{\mathrm{H}, t+1}^{a} r_{\mathrm{H}, t+1} h_{\mathrm{H}, t+1}+\lambda_{\mathrm{H}, t+1}^{2}\left(1-\kappa \frac{h_{\mathrm{H}, t+1}^{\sigma_{u}+1}}{\sigma_{u}+1}\right)\right], \\
& {\left[i_{\mathrm{H}, t}\right]: \Lambda_{\mathrm{H}, t}^{1}=\Lambda_{\mathrm{H}, t}^{2} v_{\mathrm{H}, t} g_{V t}\left(1-\phi\left(\frac{i_{\mathrm{H}, t}}{i_{\mathrm{H}, t-1}} g_{Z t-1} g_{V t}-\Lambda_{x}\right)\right)} \\
& +\beta E_{t} \Lambda_{\mathrm{H}, t+1}^{2} v_{\mathrm{H}, t+1} g_{\mathrm{Z} t}^{-\sigma_{c}} g_{V t+1} \\
& \times\left[\phi\left(\frac{i_{\mathrm{H}, t+1}}{i_{\mathrm{H}, t}} g_{Z t} g_{V t+1}-\Lambda_{x}\right) \frac{i_{\mathrm{H}, t+1}}{i_{\mathrm{H}, t}} g_{Z t}\right. \\
& \left.\quad-\frac{\phi}{2 g_{V t+1}}\left(\frac{i_{\mathrm{H}, t+1}}{i_{\mathrm{H}, t}} g_{Z t} g_{V t+1}-\Lambda_{x}\right)^{2}\right], \\
& \quad\left[u_{\mathrm{H}, t}\right]: \Lambda_{\mathrm{H}, t}^{1} q_{\mathrm{H}, t}^{a} r_{\mathrm{H}, t}=\Lambda_{\mathrm{H}, t}^{2} h_{\mathrm{H}, t}^{\sigma_{u}},
\end{aligned}
$$




$$
\begin{gathered}
{\left[B_{\mathrm{H}, t+1}\right]: \Lambda_{\mathrm{H}, t}^{1} Q(t, t+1) q_{\mathrm{H}, t}^{a}=\beta E_{t} \Lambda_{\mathrm{H}, t+1}^{1} g_{\mathrm{Z} t}^{-\sigma_{c}} q_{\mathrm{H}, t+1}^{a},} \\
\frac{\Lambda_{\mathrm{F}, t}}{\Lambda_{\mathrm{H}, t}}=c \cdot \frac{q_{\mathrm{H}, t}^{a}}{q_{\mathrm{F}, t}^{a}}=c \cdot \mathrm{rer},
\end{gathered}
$$

where $g_{Z, t}=\frac{Z_{t}}{Z_{t-1}}, g_{V, t}=\frac{V_{t}}{V_{t-1}}, g_{A, t}=\frac{A_{t}}{A_{t-1}}$, and $c$ is a constant. Equations (19) and (20) are the optimality conditions for consumption and labor. The lefthand side of equation (21) denotes the value of capital installed today, and it is equal to the expected future value, which depends on the rental rate times the utilization rate and depreciation rate. Similarly, equation (22) gives the standard optimality condition for investment. The left-hand side of the equation gives the loss of today's utility due to an additional unit of investment today, which is equated to the discounted expected future utility gains as a result of an additional investment today. The presence of investment adjustment costs smoothes changes in investment. In addition, an increase in the country-specific technological factor $v_{\mathrm{H}, t}$ reduces the cost of an extra investment today. The first-order condition for a capital utilization rate, given by equation (23), sets the marginal benefit from utilizing an extra unit of capital, given by the rental price for capital services, to the marginal user cost. The marginal user cost increases with an extra unit of capital utilization due to increased depreciation and decreases with higher investmentspecific technogical shift as it lowers the replacement cost of capital. Equation (24) gives the optimality condition for bonds. The loss of utility today in buying an additional unit of bond is equated to the expected discounted utility gains in the future. Finally, equation (25) gives the efficient risk-sharing condition obtained by combining the optimality conditions for bonds in home and foreign countries.

\section{ESTIMATION}

\subsection{Data}

I treat the United States as the home country, whereas the rest of the world (ROW) has been combined and designated as the foreign country. I use quarterly data on real GDP, real consumption, and real investment from both the United States and the ROW, and the U.S. real exchange rate and terms of trade to estimate the model. For the ROW, the GDP, consumption, and investment series have been aggregated over Canada, Japan, Australia, and 15 European countries (Austria, Belgium, Denmark, Finland, France, Germany, Greece, Ireland, Italy, Norway, Netherlands, Portugal, Spain, Sweden, and the United Kingdom). ${ }^{14}$

The sample period ranges from 1973:02 to 2007:04, at quarterly frequency. I take natural $\operatorname{logs}$ and the first differences of GDP, consumption, and investment series to compute the growth rate. I also take the natural log of the real exchange rate and terms of trade series. Because they are already stationary in levels, no further detrending is carried out. All series are multiplied by 100 and demeaned. The first row of panel A in Table 1 reports the standard deviations of the growth rates. The consumption growth rate is roughly two-thirds as volatile as the output 
TABLE 1. Second moments, volatilities, and correlations

Panel A

\begin{tabular}{|c|c|c|c|c|c|c|c|c|}
\hline \multirow[b]{2}{*}{ Std. dev.(in \%) } & \multicolumn{3}{|c|}{ United States } & \multicolumn{3}{|c|}{ ROW } & \multirow[b]{2}{*}{ rer } & \multirow[b]{2}{*}{ tot } \\
\hline & $\Delta \operatorname{gdp}_{1}$ & $\Delta c_{1}$ & $\Delta i_{1}$ & $\Delta \operatorname{gdp}_{2}$ & $\Delta c_{2}$ & $\Delta i_{2}$ & & \\
\hline Data & 0.80 & 0.51 & 2.05 & 0.44 & 0.37 & 1.13 & 9.01 & 6.61 \\
\hline Benchmark & 0.61 & 0.52 & 2.02 & 0.55 & 0.40 & 2.30 & 1.13 & 1.61 \\
\hline Benchmark, bond & 0.61 & 0.69 & 2.07 & 0.67 & 0.51 & 2.15 & 0.84 & 1.20 \\
\hline $\mathrm{CD}$, bond & 0.82 & 0.68 & 1.96 & 0.71 & 0.54 & 2.71 & 8.39 & 11.99 \\
\hline $\mathrm{CD}$ & 1.18 & 0.86 & 2.10 & 0.68 & 0.47 & 1.78 & 1.12 & 1.61 \\
\hline No adj. cost & 0.81 & 0.59 & 3.19 & 0.62 & 0.46 & 2.87 & 1.17 & 1.67 \\
\hline \multirow[t]{2}{*}{ No utilization } & 0.67 & 0.75 & 2.19 & 0.55 & 0.75 & 4.25 & 1.67 & 2.38 \\
\hline & \multicolumn{6}{|c|}{ Panel B } & & \\
\hline
\end{tabular}

\begin{tabular}{lccccr}
\hline Other correlations & $\begin{array}{c}\text { rer, } \\
c_{1}-c_{2}\end{array}$ & $\begin{array}{c}\text { tot, } \\
\mathrm{gdp}_{1}-\mathrm{gdp}_{2}\end{array}$ & $\begin{array}{c}\mathrm{gdp}_{1}, \\
\mathrm{gdp}_{2}\end{array}$ & $\begin{array}{c}c_{1}, \\
c_{2}\end{array}$ & \multicolumn{1}{c}{$\begin{array}{c}i_{1}, \\
i_{2}\end{array}$} \\
\hline Data & -0.20 & -0.29 & 0.57 & 0.34 & 0.41 \\
Benchmark & -0.31 & -0.34 & 0.43 & 0.20 & -0.43 \\
Benchmark, bond & -0.31 & -0.34 & 0.52 & 0.30 & -0.44 \\
CD, bond & 0.29 & -0.14 & 0.45 & 0.61 & 0.17 \\
CD & 0.90 & 0.45 & 0.31 & 0.61 & -0.11 \\
No adj. cost & -0.22 & -0.25 & 0.21 & 0.19 & -0.58 \\
No utilization & -0.04 & -0.15 & 0.53 & 0.75 & -0.61 \\
\hline
\end{tabular}

Notes: The top and bottom panels of the table report the second moment results from the estimated benchmark and alternative models. The second moments from the models are evaluated by simulating them 100 times with 139 periods each at the posterior modes.

growth rate for the United States and three-fourths as volatile as the output growth rate for the ROW. Furthermore, the investment growth rate is roughly three times as volatile as the output for both regions. The levels of the real exchange rate and terms of trade are highly volatile, around 9.01 and 6.61, respectively.

The first row of Panel $\mathrm{B}$ in Table 1 reports the international correlations. ${ }^{15}$ First, the correlations between the real exchange rate and the relative consumption across countries and terms of trade and relative output are both negative $(-0.20$ and -0.29 , respectively). Second, the cross-country output correlation exceeds the cross-country consumption correlation ( 0.57 and 0.34 , respectively). Finally, the cross-country investment correlation is positive, around 0.41 .

\subsection{Priors and Methodology}

Following Rabanal and Tuesta (2010), I assume that the deep parameters in both countries are the same. I calibrate some of the deep parameters that are difficult to identify. The quarterly depreciation rate is set to 0.025 and the discount rate to 0.99 . I set thef $\sigma_{c}=2$ and home bias $\omega=0.85$, which is standard in this 
literature. Following Raffo (2007 and 2010), I set steady state hours to 0.30, which is consistent with the fraction of time endownment dedicated to market activities of $30 \%$ percent in steady state. As a standard, I set the steady-state utilization rate to 1 . The rest of the deep parameters are estimated and their prior distributions are summarized in Table 2. All but the capital share parameter are rather diffuse and are taken from Smets and Wouters (2007) and Rabanal and Tuesta (2010). I use more informative priors for the capital share parameter, which is less likely to be a source of controversy. The demeaned vector of observables is

$$
Z_{t}=\left[\mathrm{dlGDP}_{\mathrm{H}, t}, \mathrm{dlGDP}_{\mathrm{F}, t}, \mathrm{dl}_{\mathrm{H}, t}, \mathrm{dl}_{\mathrm{F}, t}, \mathrm{dl}_{\mathrm{H}, t}, \mathrm{dl}_{\mathrm{F}, t}, 1 \mathrm{RER}_{t}, \mathrm{ITOT}_{t}\right],
$$

where 1 and $\mathrm{dl}$ stand for $\log$ and $\log$ difference, respectively. ${ }^{16}$

Implementation of Bayesian estimation requires several steps. The first step is to write the solution to the general equilibrium model in a state-space representation, followed by the formulation of the likelihood function of the solution system using the Kalman filter as the second step. The third step combines the likelihood function with the priors for parameters to form the posterior density function. Because the posterior distribution is nonlinear and is a complicated function of the deep parameters, the final step involves computing it using sampling-like methods such as the Metropolis-Hastings algorithm. ${ }^{17}$

\section{RESULTS}

\subsection{Parameter Estimates and Second Moments}

Table 2 reports the posterior modes along with the 5 th and 95 th percentiles of the posterior distribution for the benchmark case. My results are based on 250,000 draws from the posterior distribution. ${ }^{18}$ As in Smets and Wouters (2007), the data appear to be quite informative regarding the volatility and persistence of the exogenous disturbances. Almost all the shocks appear to be very persistent, with the exception of foreign preference and IST shocks. The posterior mode estimates show that IST shocks are the most volatile structural shocks. However, the data contain less information regarding the Frisch elasticity parameter, because the posterior mean is close to the mean of the prior distribution. The estimated value of $\tau$ implies a labor elasticity of 1 . The elasticity of substitution is estimated to be around 2.64, which is higher than the values in Heathcote and Perri (2002) and Rabanal and Tuesta (2010), and lower than the value in Enders and Muller (2009). The parameter governing the elasticity of investment adjustment costs is consistent with Christiano et al. (2005). I pin down the values of $\kappa=0.001$ and $\sigma_{u}=0.04$ from the estimated parameters, equilibrium Euler equation of capital utilization rate, and law of motion of capital evaluated in the steady state. ${ }^{19}$ Based on the posterior estimates of the shocks, it is difficult to draw comparisons with other related papers in the literature. Hence, I look at the contribution of each shock in causing fluctuations in the observables by performing a variance decomposition exercise in the following sections. 
TABLE 2. Prior and posterior distributions of the model's parameters

\begin{tabular}{|c|c|c|c|c|c|c|c|}
\hline \multirow[b]{2}{*}{ Parameter } & \multirow[b]{2}{*}{ Description } & \multicolumn{3}{|c|}{ Prior distribution } & \multicolumn{3}{|c|}{ Posterior distribution } \\
\hline & & Distribution & Mean & Std. dev. & Mean & $5 \%$ & $95 \%$ \\
\hline$(\tau-1)$ & Inverse of Frisch elasticity & Normal & 1.0 & 0.25 & 1.0021 & 0.5835 & 1.4039 \\
\hline$\theta$ & Elasticity of substitution & Normal & 1.5 & 0.25 & 2.6443 & 2.3940 & 2.9169 \\
\hline$\phi$ & Investment adj. cost elasticity & Normal & 4.0 & 1.0 & 2.5544 & 2.1533 & 4.1900 \\
\hline$\alpha$ & Capital share in production & Normal & 0.30 & 0.05 & 0.3976 & 0.3547 & 0.4401 \\
\hline$\rho_{\mathrm{H}}^{a}$ & Persistence of home neutral tech. shock & Beta & 0.5 & 0.20 & 0.9281 & 0.8874 & 0.9699 \\
\hline$\rho_{\mathrm{F}}^{a}$ & Persistence of foreign neutral tech. shock & Beta & 0.5 & 0.20 & 0.9988 & 0.9977 & 0.9998 \\
\hline$\rho_{\mathrm{H}}^{v}$ & Persistence of home IST shock & Beta & 0.5 & 0.20 & 0.7047 & 0.6038 & 0.8073 \\
\hline$\rho_{\mathrm{F}}^{v}$ & Persistence of foreign IST shock & Beta & 0.5 & 0.20 & 0.2650 & 0.1350 & 0.3921 \\
\hline$\rho_{\mathrm{H}}^{g}$ & Persistence of home preference shock & Beta & 0.5 & 0.20 & 0.9908 & 0.9855 & 0.9964 \\
\hline$\rho_{\mathrm{F}}^{g}$ & Persistence of foreign preference shock & Beta & 0.5 & 0.20 & 0.5033 & 0.1649 & 0.8286 \\
\hline$\sigma_{\mathrm{H}}^{z}($ in $\%)$ & S.D. of home neutral tech. shock & Inv Gamma & 0.5 & 1 & 0.2959 & 0.2906 & 0.3190 \\
\hline$\sigma_{\mathrm{F}}^{z}($ in $\%)$ & S.D. of foreign neutral tech. shock & Inv Gamma & 0.5 & 1 & 0.1959 & 0.1909 & 0.2411 \\
\hline$\sigma_{\mathrm{H}}^{v}($ in $\%)$ & S.D. of home IST shock & Inv Gamma & 0.5 & 1 & 2.7482 & 2.1003 & 3.3666 \\
\hline$\sigma_{\mathrm{F}}^{v}($ in $\%)$ & S.D. of foreign IST shock & Inv Gamma & 0.5 & 1 & 6.2359 & 4.6572 & 7.7965 \\
\hline$\sigma_{\mathrm{H}}^{g}($ in $\%)$ & S.D. of home preference shock & Inv Gamma & 0.1 & 1 & 1.6765 & 1.5043 & 1.8402 \\
\hline$\sigma_{\mathrm{F}}^{g}($ in $\%)$ & S.D. of foreign preference shock & Inv Gamma & 0.1 & 1 & 0.0766 & 0.0250 & 0.1324 \\
\hline$\sigma^{a}($ in $\%)$ & S.D. of world neutral tech. shock & Inv Gamma & 0.5 & 1 & 0.1595 & 0.1235 & 0.1957 \\
\hline$\sigma^{v}($ in $\%)$ & S.D. of world IST shock & Inv Gamma & 0.5 & 1 & 0.3438 & 0.1712 & 0.5127 \\
\hline
\end{tabular}

Notes: The table lists the description and the prior and posterior distributions of the structural parameters under the benchmark specification. 


\subsection{Quantities}

Panel (A) of Table 1 reports the second moments from the estimated model and data. The results in the table suggest that overall the benchmark model does a good job of matching the volatilities of the observables in the data, except for the standard deviation of the foreign investment growth rate, which is slightly overestimated.

Table 3 reports the variance decomposition of the observable variables under the benchmark model. Each entry gives the percent contribution of each shock to the fluctuations in each variable at $1,4,8,20$, and 40 quarters. According to my estimates, country-specific neutral technology and world neutral technology shocks combined account for $60 \%$ of variance in output in the United States, $40 \%$ of variance in output in the ROW, and the bulk of variance in consumption in the United States and the ROW (50 and 70\%, respectively) at all horizons. Furthermore, the contribution of IST shocks is substantial. Country-specific IST shocks account for $30 \%$ and more than $50 \%$ of the movement in outputs in the United States and the ROW, respectively. Country-specific IST shocks also cause the bulk of investment fluctuations in the United States and the ROW (more than $90 \%$ ). As for the preference shocks, I find that they contribute to around 40 and $16 \%$ of fluctuations in consumption, respectively. Finally, the world IST shocks have an insignificant impact on quantities. My results are consistent with Adolfson et al. (2007), who find that domestic shocks - in particular, technology shocksaccount for most of the variation in the domestic variables (output, consumption, and investment) at all horizons, whereas the open economy shocks play a less important role.

\subsection{Relative Prices}

Turning to the relative prices in Table 1, the model clearly underestimates the volatilities of the real exchange rate and terms of trade at 1.13 and 1.61 , respectively. Table 3 shows that the IST shocks account for about $38 \%$ of fluctuations in these variables on impact, increasing to about $45 \%$ in the long run. Neutral technology shocks play a substantial role in impact (around 50\%), but have a less important role at medium and long horizons. In contrast to Adolfson et al. (2007), I find that the closed economy shocks account for most of the variations in international relative prices, whereas the open economy shocks, such as world neutral technology and world IST shocks, do not cause any variation. This is not surprising because the two countries are symmetric and the world technology shocks simultaneously affect both domestic and foreign variables in a similar way. Hence, the relative prices, which are expressed as ratios of domestic and foreign variables, remain unaffected as a result of these shocks.

Real exchange rate puzzle. Panel (B) of Table 1 reports the model-based correlations, which are evaluated by simulating the model 100 times with 139 
TABLE 3. Variance decomposition in the benchmark model

\begin{tabular}{|c|c|c|c|c|c|c|c|c|}
\hline \multirow[b]{2}{*}{ Percent variance } & \multicolumn{3}{|c|}{ United States } & \multicolumn{3}{|c|}{ ROW } & \multirow[b]{2}{*}{ rer } & \multirow[b]{2}{*}{ tot } \\
\hline & $\Delta y_{1}$ & $\Delta c_{1}$ & $\Delta i_{1}$ & $\Delta y_{2}$ & $\Delta c_{2}$ & $\Delta i_{2}$ & & \\
\hline \multicolumn{9}{|c|}{ Period 1} \\
\hline Home neutral tech. shocks & 49.9 & 30.49 & 3.95 & 0.92 & 2.57 & 0.2 & 34.01 & 34.01 \\
\hline Foreign neutral tech. shocks & 0.07 & 2.48 & 0.07 & 28.82 & 36.47 & 0.88 & 15.5 & 15.5 \\
\hline Home IST shocks & 30.09 & 2.22 & 92.23 & 2.21 & 0.15 & 2.1 & 12.27 & 12.27 \\
\hline Foreign IST shocks & 7.62 & 0.14 & 2.66 & 56.14 & 4.08 & 96.16 & 25.86 & 25.86 \\
\hline Home preference shocks & 1.35 & 43.02 & 0.13 & 0.06 & 17.67 & 0.12 & 12.34 & 12.34 \\
\hline Foreign preference shocks & 0 & 0 & 0 & 0.02 & 0.29 & 0 & 0.01 & 0.01 \\
\hline World neutral tech. shock & 10.85 & 19.68 & 0.58 & 11.71 & 35.23 & 0.32 & 0 & 0 \\
\hline World IST shock & 0.12 & 1.98 & 0.38 & 0.13 & 3.54 & 0.21 & 0 & 0 \\
\hline \multicolumn{9}{|c|}{ Period 4} \\
\hline Home neutral tech. shocks & 46.35 & 29.41 & 5.12 & 1.51 & 2.43 & 0.21 & 23.46 & 23.46 \\
\hline Foreign neutral tech. shocks & 0.21 & 2.38 & 0.06 & 27.71 & 33.88 & 1.56 & 12.87 & 12.87 \\
\hline Home IST shocks & 32.48 & 2.48 & 90.34 & 2.54 & 0.29 & 3.84 & 30.94 & 30.94 \\
\hline Foreign IST shocks & 8.73 & 0.15 & 2.91 & 56.03 & 4.16 & 93.29 & 19.67 & 19.67 \\
\hline Home preference shocks & 1.35 & 41.16 & 0.16 & 0.17 & 16.41 & 0.19 & 13.06 & 13.06 \\
\hline Foreign preference shocks & 0.01 & 0 & 0 & 0.03 & 0.36 & 0 & 0 & 0 \\
\hline World neutral tech. shock & 10.52 & 20.86 & 0.53 & 11.61 & 36.28 & 0.34 & 0 & 0 \\
\hline World IST shock & 0.36 & 3.56 & 0.87 & 0.4 & 6.19 & 0.55 & 0 & 0 \\
\hline \multicolumn{9}{|c|}{ Period 8} \\
\hline Home neutral tech. shocks & 45.63 & 29.53 & 4.73 & 1.49 & 2.44 & 0.23 & 21.13 & 21.13 \\
\hline Foreign neutral tech. shocks & 0.21 & 2.37 & 0.08 & 27.01 & 33.85 & 1.59 & 14.3 & 14.3 \\
\hline Home IST shocks & 33.28 & 2.48 & 90.57 & 3.19 & 0.33 & 3.91 & 32.49 & 32.49 \\
\hline Foreign IST shocks & 8.85 & 0.18 & 3.13 & 56.35 & 4.18 & 93.18 & 14.29 & 14.29 \\
\hline Home preference shocks & 1.33 & 41.08 & 0.15 & 0.19 & 16.4 & 0.19 & 17.79 & 17.79 \\
\hline Foreign preference shocks & 0.01 & 0 & 0 & 0.03 & 0.36 & 0 & 0 & 0 \\
\hline World neutral tech. shock & 10.29 & 20.81 & 0.5 & 11.3 & 36.25 & 0.33 & 0 & 0 \\
\hline World IST shock & 0.41 & 3.55 & 0.85 & 0.45 & 6.19 & 0.56 & 0 & 0 \\
\hline \multicolumn{9}{|c|}{ Period 20} \\
\hline Home neutral tech. shocks & 45.46 & 29.63 & 4.8 & 1.49 & 2.43 & 0.24 & 15.52 & 15.52 \\
\hline Foreign neutral tech. shocks & 0.2 & 2.36 & 0.08 & 26.91 & 33.81 & 1.57 & 17.14 & 17.14 \\
\hline Home IST shocks & 33.84 & 2.52 & 90.4 & 3.26 & 0.41 & 5.18 & 28.17 & 28.17 \\
\hline Foreign IST shocks & 8.69 & 0.19 & 3.35 & 56.4 & 4.21 & 91.95 & 14.63 & 14.63 \\
\hline Home preference shocks & 1.31 & 41.02 & 0.14 & 0.19 & 16.38 & 0.19 & 24.55 & 24.55 \\
\hline Foreign preference shocks & 0.01 & 0 & 0 & 0.03 & 0.36 & 0 & 0 & 0 \\
\hline World neutral tech. shock & 10.08 & 20.73 & 0.46 & 11.26 & 36.2 & 0.32 & 0 & 0 \\
\hline World IST shock & 0.41 & 3.55 & 0.78 & 0.46 & 6.2 & 0.55 & 0 & 0 \\
\hline \multicolumn{9}{|c|}{ Period 40} \\
\hline Home neutral tech. shocks & 45.53 & 29.62 & 4.93 & 1.49 & 2.43 & 0.24 & 10.66 & 10.66 \\
\hline Foreign neutral tech. shocks & 0.2 & 2.36 & 0.09 & 26.92 & 33.79 & 1.61 & 21.49 & 21.49 \\
\hline Home IST shocks & 33.8 & 2.53 & 90.25 & 3.29 & 0.42 & 5.21 & 30.31 & 30.31 \\
\hline Foreign IST shocks & 8.68 & 0.19 & 3.36 & 56.37 & 4.22 & 91.88 & 13.41 & 13.41 \\
\hline Home preference shocks & 1.32 & 41.05 & 0.14 & 0.19 & 16.37 & 0.19 & 24.13 & 24.13 \\
\hline Foreign preference shocks & 0.01 & 0 & 0 & 0.03 & 0.36 & 0 & 0 & 0 \\
\hline World neutral tech. shock & 10.06 & 20.69 & 0.45 & 11.26 & 36.19 & 0.32 & 0 & 0 \\
\hline World IST shock & 0.41 & 3.55 & 0.78 & 0.46 & 6.22 & 0.55 & 0 & 0 \\
\hline
\end{tabular}

Note: The table reports the forecast error variance decomposition at different horizons. 
periods each at the posterior means of the parameters and applying the HodrickPrescott filter with smoothing parameter equal to 1,600. My estimated benchmark model does a good job of generating a negative correlation between the real exchange rate and relative consumption (around -0.31 ), thus resolving the real exchange rate puzzle.

Table 4, which systematically evaluates the role of each shock in explaining the puzzle, reveals that although both IST and preference shocks can independently account for this puzzle, neutral technology shocks fail to do so. When neutral technology shocks are the only driving forces, the model predicts a strong positive correlation between the real exchange rate and relative consumption (around 0.97). The log-linearized equation for the real exchange rate is ${ }^{20}$

$$
\text { rêr }=\alpha_{c}\left(\hat{c}_{\mathrm{H}, t}-\hat{c}_{\mathrm{F}, t}\right)-\alpha_{l}\left(\hat{l}_{\mathrm{H}, t}-\hat{l}_{\mathrm{F}, t}\right)-\left(\hat{g}_{\mathrm{H}, t}-\hat{g}_{\mathrm{F}, t}\right)
$$

where $\alpha_{c}, \alpha_{l}$ are positive constants. A positive neutral technology shock in country $\mathrm{H}$ shifts its production possibility frontier upward, leading to an increase in output, consumption, investment, and hours in country H. Because of full insurance under complete markets, consumption in country F also goes up. Strong wealth effects on consumption cause relative consumption to increase more than relative labor, leading to a depreciation of the real exchange rate, as shown in Figure 3c. This leads to a high positive correlation between the real exchange rate and relative consumption.

The preference shocks directly affect the marginal rate of substitution between home and foreign consumption, as shown in equation (27). The term $\left(\hat{g}_{\mathrm{H}, t}-\right.$ $\hat{g}_{\mathrm{F}, t}$ ), which reflects the movement originating from the taste shocks, makes the real exchange rate appreciate on impact. Impulse response results from a unit preference shock in country $\mathrm{H}$, as plotted in Figure 3, show that the real exchange rate appreciates (Figure 3c) when relative consumption (Figure 3a) also rises, hence resolving the puzzle.

Finally, a positive IST shock in the home country alters the relative price between domestic investment and domestic consumption. Cheaper investment opportunities creates strong incentives to accumulate capital straight away. Hence, domestic firms increase the utilization of installed capital, so that more resources are available. Domestic labor increases for two reasons. First, a higher utilization rate increases the marginal product of labor, causing labor hours to increase. Second, the zero wealth effect on hours implied by GHH preferences makes the labor response stronger. Furthermore, the increase in hours and the capital utilization rate stimulates domestic output. Because of the presence of capacity utiltization, domestic consumption rises, although less than domestic hours. ${ }^{21}$ In equation (4.1), the rise in relative consumption is offset by the rise in relative labor, causing the real exchange rate appreciation. This can also be seen in Figure $3 c$, where the real exchange rate appreciates simultaneously with the rise in relative consumption (Figure 3a) after a unit positive IST shock in country $\mathrm{H}$. 

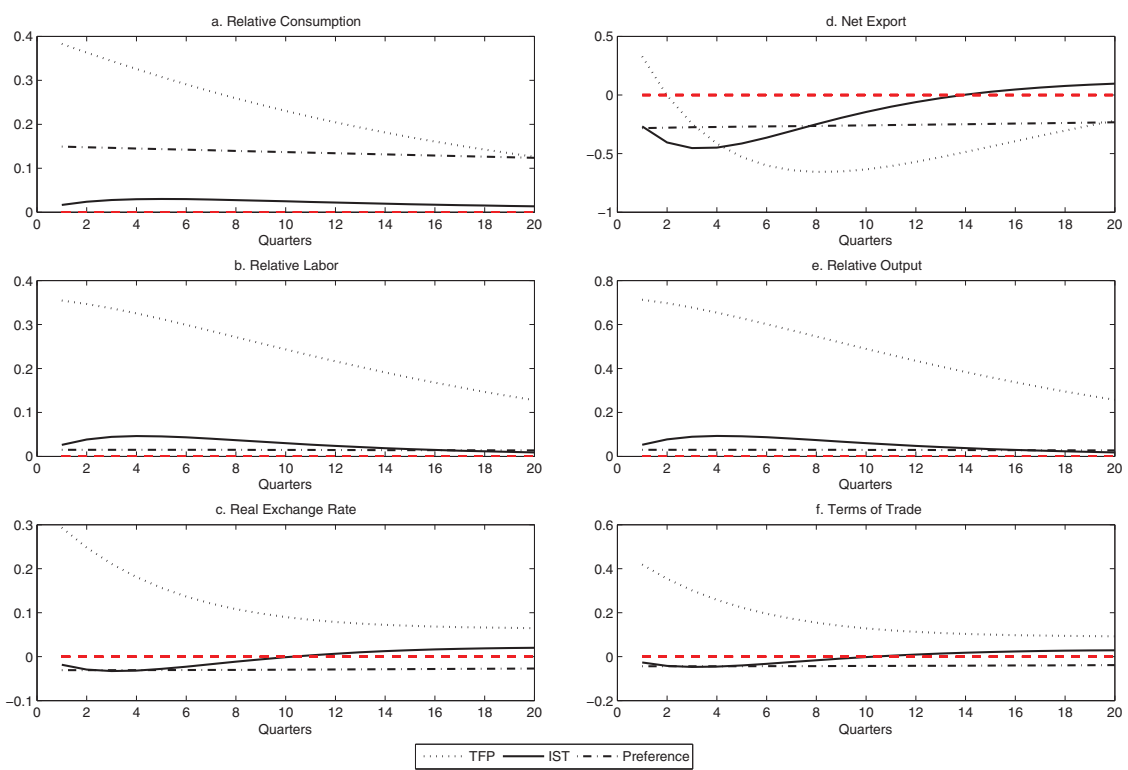

FIGURE 3. IRF from one unit positive structural shock in home country. Responses of model variables to a unit IST (solid line), neutral technology (dotted line), and preference (dashed-dotted line) shock in the home country. All the impulse responses are computed at the mode of posterior distribution under benchmark setting.

The preceding result is consistent with the recent work by Raffo (2010), who, using a calibration exercise, shows that IST shocks combined with GHH preferences, investment adjustment costs, and capacity utilization can resolve the puzzle. However, these results are in stark contrast with Mandelman et al. (2011). First, using the observations on relative prices of investment across countries, they show that IST shocks are unit-root nonstationary and cointegrated across countries. Whereas IST shocks in my benchmark specification capture all sources of unexplained variations in both investment and productive capital, they assume that IST shocks take into account only a specific source of the variation in investment. Second, they find that these shocks are unable to resolve any of the international price puzzles. In Appendix E, I discipline the behavior of IST shocks by including observations on the relative price of investment and find that the estimated model cannot account for the international price puzzles, confirming the findings in Mandelman et al. (2011). Hence, to reiterate, the benchmark results are not insensitive to the stochastic processes governing the shocks and types of observables.

The world technology does not have interesting economic implications and hence will not be discussed further. ${ }^{22}$ 
TABLE 4. Contribution of each shock

\begin{tabular}{|c|c|c|c|c|c|c|}
\hline & \multirow{2}{*}{\multicolumn{2}{|c|}{ Std. dev. }} & \multicolumn{4}{|c|}{ Cross correlations } \\
\hline & & & \multirow{2}{*}{$\begin{array}{c}\text { rer, } \\
c_{1}-c_{2}\end{array}$} & \multirow{2}{*}{$\begin{array}{c}\text { tot } \\
y_{1}-y_{2}\end{array}$} & \multirow{2}{*}{$\begin{array}{l}y_{1} \\
y_{2}\end{array}$} & \multirow{2}{*}{$\begin{array}{l}c_{1} \\
c_{2}\end{array}$} \\
\hline & rer & tot & & & & \\
\hline Data & 9.01 & 6.61 & -0.20 & -0.29 & 0.57 & 0.34 \\
\hline Benchmark & 1.13 & 1.61 & -0.31 & -0.34 & 0.43 & 0.20 \\
\hline Home neutral technology & 0.32 & 0.46 & 0.94 & 0.92 & 0.04 & 0.99 \\
\hline Foreign neutral technology & 0.15 & 0.22 & 0.95 & 0.92 & 0.26 & 0.99 \\
\hline Neutral technology shocks & 0.37 & 0.53 & 0.97 & 0.95 & 0.01 & 0.52 \\
\hline Home preference & 0.29 & 0.42 & -0.99 & -0.99 & 0.47 & -0.99 \\
\hline Foreign preference & 0.003 & 0.005 & -0.99 & -0.99 & 0.99 & -0.94 \\
\hline Preference shocks & 0.31 & 0.45 & -0.99 & -0.99 & 0.50 & -0.99 \\
\hline Home IST & 0.53 & 0.76 & -0.88 & -0.94 & 0.73 & -0.91 \\
\hline Foreign IST & 0.41 & 0.59 & -0.83 & -0.91 & 0.80 & -0.66 \\
\hline IST shocks & 1.03 & 1.48 & -0.87 & -0.93 & 0.37 & -0.47 \\
\hline World neutral tech. & 0.00 & 0.00 & 0.93 & 0.16 & 1.00 & 1.00 \\
\hline World IST & 0.00 & 0.00 & 0.95 & 0.00 & 1.00 & 1.00 \\
\hline
\end{tabular}

Note: The table reports the model predictions for the standard deviations of international relative prices and their correlations with quantities with only one shock at a time.

Terms of trade puzzle. Again, on analyzing the role of each shock in Table 4, I find that the neutral technology shock predicts a high and near-perfect correlation between terms of trade and relative output, around 0.95 . The log-linearized expression for terms of trade can be expressed as ${ }^{23}$

$$
\text { tôt }=d_{1} d_{2} \frac{\mathrm{nx}}{y}+d_{1}\left(\mathrm{~g} \hat{\mathrm{d}} \mathrm{p}_{\mathrm{H}}-\mathrm{gd \hat {d }} \mathrm{F}_{\mathrm{F}},\right.
$$

where $\frac{\mathrm{nx}}{y}$ is net export as defined in equation (16) and $d_{1}, d_{2}$ are positive constants. Equation (28) suggests that all the movements in tôt are due to the movements in the two offsetting forces - trade balance, ${ }^{24}$ which captures the relative demand effect, and relative output, which captures the relative supply effect. At the onset of a positive neutral technology shock in country $\mathrm{H}$, domestic output rises relative to foreign output, making the latter relatively scarce in the international markets. In other words, the value of imports increases relative to the value of exports. Thus relative supply effect rises and dominates the relative demand effect, causing the terms of trade to depreciate (Figure 3f) when relative output is also rising (Figure 3e). This leads to a strong positive correlation between terms of trade and relative output if neutral productivity shocks are the main sources of business cycle fluctuations. 
Under the preference shocks, the model predicts a high negative correlation of about -0.99 (Table 4). By increasing domestic consumption on impact, a positive preference shock in country $H$ acts as a demand shock. To meet the increased domestic demand, country $H$ increases its domestic inputs (which further stimulates output) and borrowing from abroad. The fall in the trade balance (Figure $3 d$ ) offsets the rise in relative output (Figure $3 \mathrm{e}$ ), leading to a terms of trade appreciation (Figure 3f).

Finally, IST shocks can also account for the puzzle successfully by generating a negative correlation between terms of trade and relative output (around -0.93) in Table 4. Similarly to a preference shock, an IST shock creates huge domestic demand without directly affecting current production possibilities. This domestic demand is partly met by increasing domestic inputs (labor and capacity utilization rate) and partly by increasing imports of foreign goods (via increased domestic absorption), thus deteriorating the trade balance. Increased inputs further stimulate domestic output, leading to a rise in relative supply in equation (28). However, the large fall in trade balance (Figure 3d) offsets the rise in relative supply (Figure $3 \mathrm{e}$ ), causing the terms of trade to appreciate as shown in Figure $3 \mathrm{f}$.

Twin volatility puzzle. Panel (A) of Table 1 shows that my estimated benchmark model only partially accounts for high volatilities in the levels of the real exchange rate and terms of trade, around 12 and 24\%, respectively. A possible explanation is that the data suggest there is a deviation from the law of one price. ${ }^{25}$ However, IST shocks cause the highest model-based volatilities in these relative prices. Let us understand the channels causing high volatility in terms of trade. ${ }^{26}$

With only neutral technology shocks, the volatility in terms of trade is very low compared with the data (0.53 vs. 6.61). Whereas home neutral tecnology shocks predict a volatility of around 0.46 , foreign neutral techlonogy shocks predict a volatility of only 0.22 . Raffo (2007) shows that IRBC models with GHH preferences and neutral technology shocks can generate high volatilities in domestic absorption and hence net exports. However, the same neutral technology shock affects both the net exports and the relative output simultaneously in equation (28), making the overall volatility in terms of trade low.

Table 4 shows that the preference shocks generate a volatility of 0.45 in terms of trade, which is again quite low compared with the data. In addition, most of this volatility is attributed to the home preference shocks. A positive preference shock in the domestic country has a positive effect on domestic consumption but a negative crowding-out effect on domestic investment. Because domestic absorption constitutes both domestic consumption and domestic investment, a rise in consumption is offset by a fall in investment after a preference shock, making the overall volatility in domestic absorption low. This results in low variability in net exports in equation (28). Moreover, a positive preference shock stimulates domestic output indirectly through increased domestic inputs, leading to low volatility in the relative supply term in equation (28). This makes the overall volatility in terms of trade low. 
Finally, let us look at the contribution of IST shocks, as shown in Table 4. Whereas home IST shocks generate a volatility of 0.76 , the foreign IST shocks generate one of 0.59. Overall, the IST shocks are successful in accounting for the high volatility in terms of trade to some extent, making it as high as 1.48 . Similarly to the preference shock, a positive IST in the home country stimulates domestic output indirectly through increased labor and capital utilization. However, in contrast to the preference shock, it induces households to increase investment, as it has become relatively cheaper than consumption. In addition, because of the presence of variable capacity utilization, domestic consumption also rises, making the volatility of domestic absorption (hence net exports) higher. In equation (28), therefore, a huge fall in net exports offsets a small rise in relative output, inducing high volatility in terms of trade.

\subsection{Other Correlations}

Table 1, Panel B, reports cross-country consumption, output, and investment correlations. My estimated benchmark model successfully predicts a cross-country output correlation ( 0.43$)$ higher than the cross-country consumption correlation (0.20). Most of the macroeconomic models predict the opposite, regardless of the asset market structure and real or nominal rigidities. Table 4 reveals that both IST and preference shocks can predict the correct ranking between the two cross correlations, as in the data. However, both the demand shocks predict a negative cross-country consumption correlation, which is counterfactual. Furthermore, Table 1 shows that the cross-country investment correlation in the model is counterfactually negative $(-0.43)$. This is because IST shocks act as demand shocks and directly increase international borrowing. The country hit by favorable IST shocks increases domestic investment and accumulates more capital by increasing domestic inputs and imports, which induces a negative cross-country correlation between investments.

My results indicate that the introduction of a general definition of investment shocks into a stylized model is sufficient to solve the real exchange rate and terms of trade puzzles, but not enough to fully explain the twin volatility puzzle.

\section{MODEL SENSITIVITY}

\subsection{Incomplete Markets}

In this section, I explore the potential for incomplete asset markets within an IRBC framework to explain the international price puzzles. To this end, I relax the assumption of full insurance in my benchmark model. Following Heathcote and Perri (2002), I assume that only a single noncontingent bond is traded. The budget constraint faced by the households in the home country becomes

$$
\begin{aligned}
& q_{\mathrm{H}}^{a}\left(s^{t}\right)\left(W_{\mathrm{H}}\left(s^{t}\right) l_{\mathrm{H}}\left(s^{t}\right)+r_{\mathrm{H}}\left(s^{t}\right) h_{\mathrm{H}}\left(s^{t}\right) K_{\mathrm{H}}\left(s^{t}\right)\right)+q_{\mathrm{H}}^{a}\left(s^{t}\right)\left[B_{\mathrm{H}}\left(s^{t-1}\right)-\phi_{1}\left(B_{\mathrm{H}}\left(s^{t}\right)\right)\right] \\
& \quad=C_{\mathrm{H}}\left(s^{t}\right)+I_{\mathrm{H}}\left(s^{t}\right)+q_{\mathrm{H}}^{a}\left(s^{t}\right) Q\left(s^{t}\right) B_{\mathrm{H}}\left(s^{t}\right) .
\end{aligned}
$$


TABLE 5. Model comparison using log marginal likekihood

\begin{tabular}{lc}
\hline Model & Log marginal \\
\hline Benchmark & -717.689 \\
Benchmark, bond & -732.467 \\
CD, bond & -770.575 \\
CD & -1021.579 \\
No adj. cost & -806.002 \\
No utilization & -825.557 \\
\hline
\end{tabular}

Here, the single noncontingent bond $B_{t}\left(s^{t}\right)$ pays one unit of good $a$ minus a small adjustment cost in period $t+1$ in all states. $\phi_{1}($.$) is the arbitrarily small cost of$ holding the bond. Following Mandelman et al. (2011), I assume that

$$
\phi_{1}\left(B_{\mathrm{H}}\left(s^{t}\right)\right)=\frac{\psi_{1}}{2} Z\left(s^{t-1}\right)\left(\frac{B_{\mathrm{H}}\left(s^{t}\right)}{Z\left(s^{t-1}\right)}\right)^{2},
$$

where $\psi_{1}$ is a parameter that is estimated. ${ }^{27}$ One advantage of Bayesian analysis is that it can be employed to assess the relative plausibility of alternative model specifications by comparing log marginal likelihood. ${ }^{28}$ Table 5 reports the log marginal likelihood based on Geweke's harmonic mean estimator. It is clear from the table that this model (header "Benchmark, bond") has an inferior fit compared to the benchmark ( -732.467 vs. -717.689$)$. Furthermore, second moments results under this specification, as reported in Table 1, are very close to the benchmark model. This is not surprising, because a wealth of literature shows that when shocks are stationary or there are positive spillovers, incomplete markets are indistinguishable from complete markets. ${ }^{29}$ Hence, in the presence of stationary country-specific shocks and positive spillovers captured by world technology shocks, this model specification fails to outperform the benchmark model.

Corsetti et al. (2008) demonstrate that an incomplete market coupled with strong wealth effects can lead to the resolution of international price puzzles. When the elasticity of substitution is subtantially low and asset markets are incomplete, an improvement in total-factor productivity in the home country leads to highly volatile responses of international relative prices. This further generates strong endogenous wealth effects, inducing an appreciation of international relative prices as home consumption and output rise. Finally, the negative international transmission mechanism implied by their model predicts that cross-country consumption correlation is lower than cross-country output correlation. In the spirit of their model, I change my benchmark preferences to Cobb-Douglas preferences, given as

$$
U\left(C_{i}\left(s^{t}\right), 1-l_{i}\left(s^{t}\right)\right)=g_{i}\left(s^{t}\right)\left(\frac{\left[C_{i}\left(s^{t}\right)^{\mu}\left(1-l_{i}\left(s^{t}\right)\right)^{(1-\mu)}\right]^{\left(1-\sigma_{c}\right)}-1}{\left(1-\sigma_{c}\right)}\right) .
$$


TABLE 6. Posterior mean under alternative specifications

\begin{tabular}{|c|c|c|c|c|c|c|}
\hline Parameters & Benchmark & $\begin{array}{l}\text { Benchmark, } \\
\text { bond }\end{array}$ & $\begin{array}{l}\text { CD, } \\
\text { bond }\end{array}$ & $\mathrm{CD}$ & $\begin{array}{c}\text { No adjustment } \\
\text { cost }\end{array}$ & $\begin{array}{c}\text { No } \\
\text { utilization }\end{array}$ \\
\hline$(\tau-1)$ & 1.00 & 0.99 & - & - & 1.00 & 0.99 \\
\hline$\mu$ & - & - & 1.00 & 1.00 & - & - \\
\hline$\theta$ & 2.64 & 2.65 & 0.51 & 2.98 & 2.59 & 2.08 \\
\hline$\phi$ & 2.55 & 2.61 & 2.55 & 2.30 & - & 2.67 \\
\hline$\alpha$ & 0.40 & 0.41 & 0.31 & 0.61 & 0.41 & 0.22 \\
\hline$\psi_{1}$ & - & 0.0001 & 0.0004 & - & - & - \\
\hline$\rho_{\mathrm{H}}^{a}$ & 0.93 & 0.94 & 0.99 & 0.99 & 0.96 & 0.94 \\
\hline$\rho_{\mathrm{F}}^{a}$ & 0.99 & 0.61 & 0.54 & 0.99 & 0.99 & 0.98 \\
\hline$\rho_{\mathrm{H}}^{g}$ & 0.99 & 0.99 & 0.88 & 0.97 & 0.96 & 0.50 \\
\hline$\rho_{\mathrm{F}}^{g}$ & 0.50 & 0.59 & 0.99 & 0.90 & 0.94 & 0.99 \\
\hline$\rho_{\mathrm{H}}^{v}$ & 0.70 & 0.72 & 0.51 & 0.57 & 0.96 & 0.65 \\
\hline$\rho_{\mathrm{F}}^{v}$ & 0.27 & 0.24 & 0.15 & 0.27 & 0.53 & 0.33 \\
\hline$\sigma_{\mathrm{H}}^{z}($ in $\%)$ & 0.29 & 0.29 & 0.25 & 0.29 & 0.30 & 0.29 \\
\hline$\sigma_{\mathrm{F}}^{z}($ in $\%)$ & 0.19 & 0.19 & 0.17 & 0.19 & 0.20 & 0.20 \\
\hline$\sigma_{\mathrm{H}}^{g}($ in $\%)$ & 1.68 & 3.67 & 1.46 & 2.33 & 1.66 & 0.12 \\
\hline$\sigma_{\mathrm{F}}^{g}($ in $\%)$ & 0.08 & 0.25 & 0.99 & 0.83 & 1.16 & 1.82 \\
\hline$\sigma_{\mathrm{H}}^{v}($ in $\%)$ & 2.75 & 2.81 & 2.87 & 2.77 & 0.38 & 3.12 \\
\hline$\sigma_{\mathrm{F}}^{v}($ in $\%)$ & 6.24 & 6.05 & 7.45 & 3.95 & 0.30 & 12.55 \\
\hline$\sigma^{a}($ in $\%)$ & 0.16 & 0.23 & 0.19 & 0.15 & 0.10 & 0.77 \\
\hline$\sigma^{v}($ in $\%)$ & 0.34 & 0.41 & 0.36 & 0.25 & 0.19 & 0.30 \\
\hline
\end{tabular}

I estimate this new model specification under bond economy. Table 6, which gives the posterior estimates (header "CD, bond"), reveals that the estimated value of the elasticity of substitution is around 0.5 . This value is much lower than the estimates of 2.64 under the benchmark case but much higher than the value of 0.23 as found in Enders and Muller (2009).

Table 1 indicates that this specification can simultaneously generate high volatilities in international prices (8.39 and 11.99) and resolve the terms of trade puzzle. However, the model cannot resolve the real exchange rate puzzle and predicts that cross-country consumption correlation exceeds cross-country output correlation. Furthermore, Table 7, which reports the contribution by each shock type, indicates that the neutral technology shocks are the key contributors to the second moments and outperform other shocks in bringing the model predictions closer to the data. These results are broadly in line with the findings in Corsetti et al. (2008). ${ }^{30}$ Finally, Table 5 suggests that this model is rejected in comparison with the benchmark specification. To further compare the fit across the two models, I plot the cross-correlation function generated from the models and the data as in Figure 4. Overall, the cross correlation implied by the benchmark model (red dashed-dot line) comes closer to the cross correlation obtained from the data (black 
TABLE 7. Contribution of each shock under incomplete market

\begin{tabular}{|c|c|c|c|c|c|c|}
\hline & \multicolumn{2}{|c|}{ Std. dev. } & \multicolumn{4}{|c|}{ Cross correlations } \\
\hline & & & \multirow{2}{*}{$\begin{array}{c}\text { rer, } \\
c_{1}-c_{2}\end{array}$} & \multirow{2}{*}{$\begin{array}{c}\text { tot, } \\
y 1-y 2\end{array}$} & \multirow{2}{*}{$\begin{array}{l}y_{1} \\
y_{2}\end{array}$} & \multirow{2}{*}{$\begin{array}{l}c_{1} \\
c_{2}\end{array}$} \\
\hline & rer & tot & & & & \\
\hline Data & 9.01 & 6.61 & -0.20 & -0.29 & 0.57 & 0.34 \\
\hline $\mathrm{CD}$, bond & 8.39 & 11.99 & 0.29 & -0.14 & 0.45 & 0.61 \\
\hline Neutral technology shocks & 6.00 & 8.58 & -0.95 & -0.94 & 0.38 & -0.07 \\
\hline Preference shocks & 6.34 & 9.06 & 0.79 & 0.66 & 0.34 & 0.74 \\
\hline IST shocks & 1.00 & 1.43 & 0.33 & -0.34 & 0.18 & 0.14 \\
\hline World neutral technology shock & 0.00 & 0.00 & -0.99 & -0.99 & 1.00 & 1.00 \\
\hline World IST shock & 0.00 & 0.00 & -0.98 & -0.92 & 1.00 & 1.00 \\
\hline
\end{tabular}

Note: The table reports the model (with Cobb-Douglas preferences and low elasticity of substitution) predictions for the standard deviations of international relative prices and their correlations with quantities for only one shock type at a time.

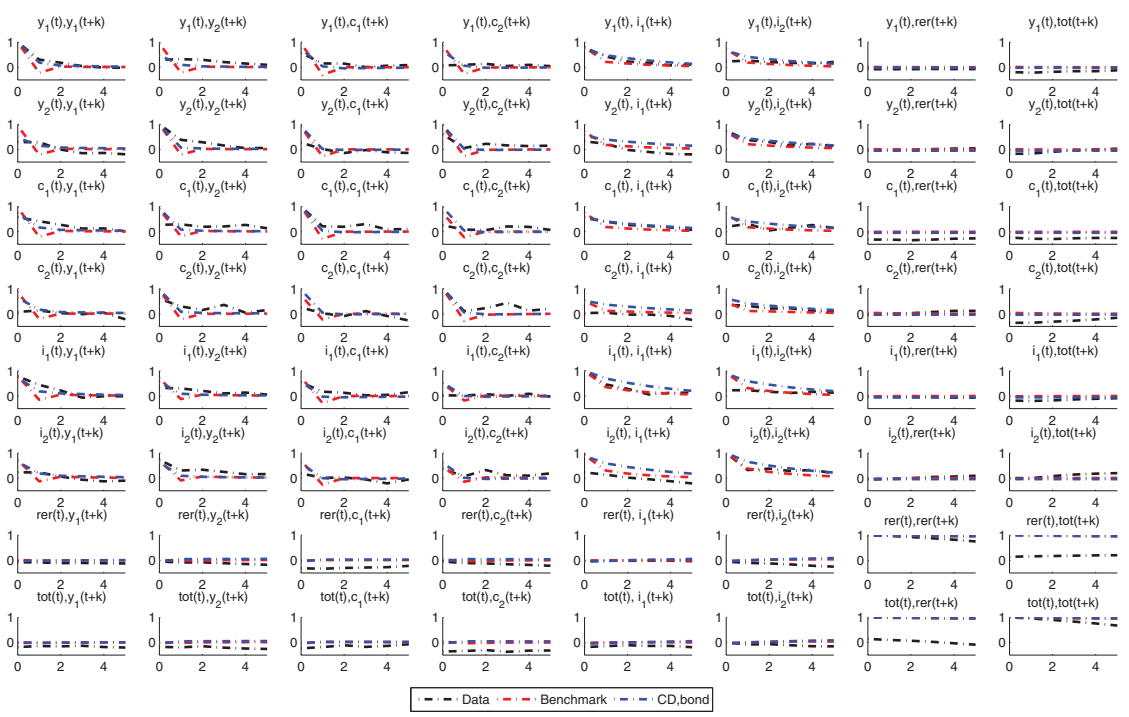

FIGURE 4. Cross correlations comparison between benchmark and " $\mathrm{CD}$, bond" models. The black, red, and blue dashed lines show the cross correlations between observables in periods $t$ and $t+k, k=0,1, \ldots, 5$ in the data, benchmark specification, and " $\mathrm{CD}$, bond" specification, respectively.

dashed-dot line) compared to this specification (blue dashed-dot line). In particular, the benchmark model does remarkably better for cross correlations between domestic and foreign consumption growth rates, and for domestic and foreign investment growth rates. 


\subsection{Real Frictions}

To investigate the quantitative roles of all the real frictions in the model, I modify the benchmark specification by shutting down one friction at a time. First, the GHH preferences are replaced with Cobb-Douglas preferences (header "CD"), given in equation (31). Whereas GHH preferences are log nonseparable in hours, CobbDouglas preferences are log separable in hours. Moreover, they imply different wealth effects on labor supply. Whereas GHH preferences imply zero wealth effects on hours, Cobb-Douglas preferences imply negative wealth effects. Second, I shut down the investment adjustment costs (header "No adj. cost") in each country by setting $\phi=0$. Last, the variable capital utilization channel is shut down (header "No utilization"). I estimate each model specification to obtain the log marginal likelihood.

Table 6 gives the posterior estimates and Table 5 gives the log marginal likelihood under all specifications. The results in Table 5 suggest that replacing GHH preferences with simple Cobb-Douglas type preferences is costliest, as the marginal likelihood falls by 304 compared to the benchmark, which means a prior that favors this model over the benchmark by a factor of $1.06 \times 10^{132}$ $(\exp (304))$ is required.

Smets and Wouters (2007) estimate a dynamic stochastic general equilibrium model with habit formation in consumption and find that the most important real friction in terms of marginal likelihood comparison is investment adjustment costs. Shutting down capacity utilization does not seem to affect their model's performance greatly. However, in the presence of GHH preferences, I find that it is costlier to shut down the endogenous capital utilization because the marginal likelihood falls by almost 108 compared to the benchmark, which means that a prior that favors the model without capacity utilization over the benchmark by a factor of $8.01 \times 10^{46}$ is needed in order to accept it after observing the data.

Furthermore, I investigate to what extent the absence of each friction hurts the model's predictive power regarding the second moments, as reported in Table 1. All the moments from other model specifications are calculated at their respective posterior means. It is evident from the table that the model with Cobb-Douglas preferences fails to resolve the real exchange rate puzzle, the terms of trade puzzle, and the consumption-output anomaly, confirming my results from the Bayes factor comparison. To understand the intuition, let us look at the log-linearized equation for the real exchange rate under these preferences. Under the complete market assumption,

$$
\text { rêr }=\Gamma_{c}\left(\hat{c}_{\mathrm{H}, t}-\hat{c}_{\mathrm{F}, t}\right)+\Gamma_{l}\left(\hat{l}_{\mathrm{H}, t}-\hat{l}_{\mathrm{F}, t}\right)-\left(\hat{g}_{\mathrm{H}, t}-\hat{g}_{\mathrm{F}, t}\right),
$$

where $\Gamma_{c}=\left(\mu\left(1-\sigma_{c}\right)-1\right)$ and $\Gamma_{l}=(\mu-1)\left(1-\sigma_{c}\right) \frac{\bar{l}}{1-\bar{l}}$ are constants. With high estimates of elasticity of substitution under this specification (around 2.98), a positive neutral technology shock fails to generate an appreciation in the real exchange rate. At the onset of a positive IST shock in this economy, relative consumption falls while relative hours rise. Unlike GHH preferences, these preferences imply 

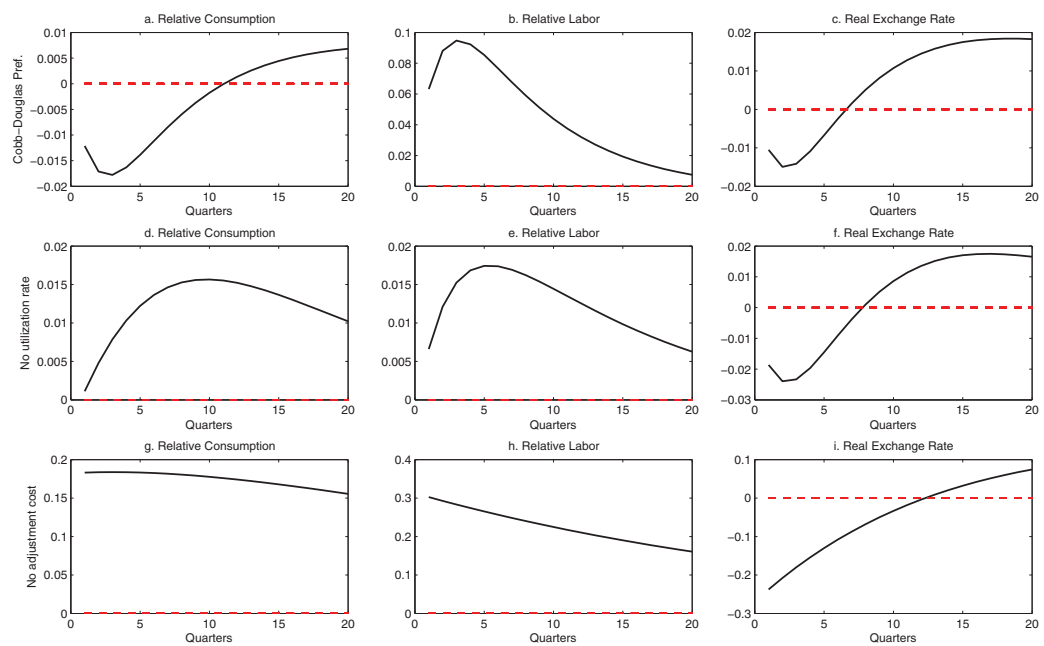

FIGURE 5. Sensitivity analysis. The estimated responses of relative consumption, relative labor, and real exchange rate to a unit IST shock under alternative specifications. Row 1: Cobb-Douglas preferences; Row 2: no capital utilization rate; Row 3: no adjustment costs. All the impulse responses are computed at the mode of the posterior distribution obtained under alternative settings.

a negative wealth effect, which make hours less volatile to the shock; thus a fall in relative consumption offsets a rise in relative hours inducing an appreciation in the real exchange rate [equation (32)]. This is also shown in Figures 5a and 5c, where relative consumption and the real exchange rate positively comove after an IST shock. Finally, after a positive preference shock in the home country, relative consumption and relative hours rise simultaneously, inducing a depreciation in the real exchange rate.

Variable capacity utilization provides an important channel for the transmission of IST shocks in the economy in two ways. First, by shifting the marginal product of labor, it induces a stronger response of hours to an IST shock. Second, it is a crucial channel for generating comovement between consumption, output, and investment after a unit IST shock. In the absence of this channel, consumption responds counterfactually and labor, output, and domestic absorption do not respond much to the shock. The impulse response analysis under this specification shows that real exchange rate and relative consumption (Figures $5 \mathrm{~d}$ and $5 \mathrm{f}$ ) positively comove after a positive IST shock, failing to address the real exchange rate puzzle. The near-zero correlation between the two, as depicted in Table 1, is attributed to the presence of the preference shocks. In addition, shutting down variable capacity utilization fails to resolve the consumption-output anomaly.

The model with no investment adjustment costs can account for the dynamics of international relative prices and resolve the real exchange rate puzzle and the terms of trade puzzle. However, this specification does badly in a marginal likelihood 
comparison, as reported in Table 5, because it overpredicts the volatilities of the quantities, especially investment series.

\section{CONCLUSION}

In this paper, I estimate an IRBC model with complete asset markets using a Bayesian approach. My theoretical model is augmented with several features, such as $\mathrm{GHH}$ preferences, variable capacity utilization, and investment adjustment costs, as well as several country-specific shocks and two world technology shocks.

The key contributions of the paper are as follows. First, although countryspecific neutral and world neutral technology shocks combined are important for explaining output and consumption fluctuations, IST shocks are important for investment and relative price fluctuations. This is because whereas TFP and world TFP shocks directly impact the current production possibilities, IST shocks directly impact international borrowings.

Second, my estimated model accounts for the real exchange rate puzzle and the terms of trade puzzle, and partially accounts for the twin volatility puzzle. My estimates establish that the two critical channels needed for the benchmark model predictions to hold are the IST shock and GHH preferences. The IST shock is critical because it creates a huge demand for investment goods and induces firms to increase labor inputs and capacity utilization. This further increases output, consumption, and domestic absorption, leading to an appreciation of international prices.

GHH preferences are critical because, combined with variable capacity utilization, they simultaneously make the labor response stronger and the consumption rise and comove with output after a positive IST shock. In addition, using a marginal likelihood comparison, I find that assuming incomplete asset markets does not affect the model's performance by much.

In a nutshell, this paper does not aim to propose a new channel or mechanism to match key moments in the international data. It instead uses an agnostic approach by combining some of the existing channels in a simple model setting and quantitatively evaluating their relative importance in explaining the dynamics of quantities and international relative prices.

\section{NOTES}

1. Ireland (2013), using a maximum likelihood approach, demonstrate that the rapid investmentspecific technological change that characterized the United States in 1990 is largely absent in the euro area.

2. This was first pointed out by Backus and Smith (1993) and as such is known as the Backus and Smith puzzle.

3. The real exchange rate is defined as the price of consumption in a foreign country relative to consumption in the domestic country. An increase in the real exchange rate typically means it has depreciated and vice versa.

4. I define the terms of trade as the ratio of import prices to export prices. An increase in the ratio means that the terms of trade have depreciated and vice versa. 
5. Under incomplete markets, productivity shocks can have a strong wealth effect if trade elasticity is low. This leads to a huge increase in demand for domestic goods and hence the appreciation of international relative prices.

6. See Greenwood et al. (1997), Fisher (2006), Altig et al. (2011), Justiniano et al. (2011), and Schmitt-Grohé and Uribe (2012).

7. Such as sticky investment prices or when capital accumulation is subject to more frictions, as in Bernanke et al. (1999) or Christiano et al. (2008). Other studies that have used similar approaches are Smets and Wouters (2003, 2007), Justiniano et al. (2010), and Rabanal and Tuesta (2010).

8. Other contributions to this literature: Christoffel et al. (2008) estimate a version of the new area-wide model using the Euro data; Kollmann (2013) estimate a two-country model with a global bank and find that banking shocks matter more for the Euro macro variables than for U.S. business cycles; de Walque et al. (2005) develop and estimate a DSGE model for the United States and the euro area and investigate the contribution of domestic and open economy shocks to international business cycle fluctuations; and Justiniano and Preston (2010) estimate a small open economy model using Canadian data and find that U.S. shocks do little to explain the variability in Canadian output, interest rates, or inflation.

9. Here $s^{t}$ denotes the history of all exogenous shocks.

10. I assume that the two countries are symmetric so that $\omega_{\mathrm{H}}=\omega_{\mathrm{F}}=\omega$.

11. An alternative solution is to allow for measurement errors in the model. However, such specification errors are usually nonfundamental, whereas the world IST shock is contained in the primitives of the model. Moreover, as Komunjer and $\mathrm{Ng}$ (2011) pointed out, adding measurement errors might eliminate stochastic singularity but could complicate identification.

12. Justiniano et al. (2011) argue that IST shocks could play a "similar economic" role to entrepreneurial net worth in the agency cost model of Carlstrom and Fuerst (1997) and stress that whereas these shocks are exogenous, net worth is endogenous.

13. For simplicity, I suppress all the terms denoting history. The complete set of first-order conditions are available in Appendix A.1.

14. For details on data definition, see Appendix C.

15. The levels of the variables are detrended using the Hodrick-Prescott filter.

16. Please see Appendix D for the measurement equations.

17. An and Schorfheide (2007) provide a detailed summary of applications of Bayesian methods in dynamic stochastic general equilibrium models.

18. I run two chains of the Metropolis-Hastings algorithm and the acceptance rates for the benchmark case are 0.34 and 0.35 . The prior distributions, posterior distributions, MCMC diagnostics for the benchmark case, and alternative specifications are available on request.

19. In the steady state, $\sigma_{u}=\frac{\bar{u} \bar{r}}{\delta}-1$ and $\kappa=\frac{\delta\left(1+\sigma_{u}\right)}{\bar{u}^{1+\sigma_{u}}}$.

20. See Appendix A.2 for a detailed derivation.

21. The dynamics of consumption is affected by IST shock through three different channels_-income effect, intertemporal substitution effect, and intratemporal substitution effect. The income effect is due to the increased productivity of the economy and is positive. The negative intertemporal substitution effect originates from the increased rate of return on current investment and persuades households to postpone current consumption for future consumption. Because of endogenous capacity utilization, I have a third effect on consumption, which is a positive intratemporal substitution effect between current consumption and current leisure. The increased marginal product for labor after a positive IST shock is an opportunity cost of current leisure in terms of current consumption. This provides agents with an incentive to substitute higher consumption today for leisure.

22. The world technology shock affects all the variables across countries in a similar way, and hence does not cause any movement in the international relative prices.

23. See Appendix A.2 for a detailed derivation.

24. Which measures the difference between domestic production and domestic absorption, as $n x=$ $Y-(C+I)$. 
25. Purchasing power parity fails to hold in the short run, and the exchange rate seems to be disconnected from the fundamentals, as pointed out by Obsfeld and Rogoff (2000).

26. The real exchange rate is related to terms of trade as

$$
\text { tôt }=\frac{1}{(2 \omega-1)} \text { rêr, }
$$

where $0<\omega<1$ and $(1-\omega)$ is the import ratio. This relationship shows that the volatility of the real exchange rate is systematically lower than the volatility of terms of trade in these classes of economies. Note that this relationship might not hold if we allowed for nontradable goods in the model.

27. Please see Appendix B for derivation of the risk-sharing condition under this economy. Following Rabanal and Tuesta (2010), I assume $\psi_{1}$ follows a Gamma distribution with mean 0.02 and standard deviation 0.014 .

28. This tool has been used successfully to make comparisons across models in Lubik and Schorfheide (2006), Smets and Wouters (2007), Justiniano et al. (2010), and Rabanal and Tuesta (2010). Fernández-Villaverde and Rubio-Ramírez (2004) argue that Bayesian inference based on marginal likelihood comparison across models is valid even if the models are non-nested, misspecified, and nonlinear.

29. Baxter and Crucini (1995) and Heathcote and Perri (2002) use a calibration approach to show that restricting asset trade to single noncontingent bonds gives model predictions similar to those for complete markets if shocks have low persistence or are transmitted rapidly across countries. This is because the relative wealth effect on the country hit by the favorable shock is very small in the presence of stationary shocks with spillovers. Rabanal and Tuesta (2010) use a Bayesian approach to show that under the assumption of producer currency pricing, the overall fit of the model with complete markets is very close to that of the model with incomplete markets.

30. In addition to the preceding channels, Corsetti et al. (2008) assumed distribution services, which enabled deviation from law of one price. As a result, their model consistently predicted higher volatility in the real exchange rate than in the terms of trade.

31. Mandelman et al. (2011) point out that when IST shocks are nonstationary, their standard deviations need to be multiplied by a factor of 7 and adjustment costs need to be set to 6 to address the correlation puzzles successfully.

\section{REFERENCES}

Adolfson, M., S. Laséen, J. Lindé, and M. Villani (2007) Bayesian estimation of an open economy DSGE model with incomplete pass-through. Journal of International Economics 72(2), 481-511.

Altig, D., L. Christiano, M. Eichenbaum, and J. Linde (2011) Firm-specific capital, nominal rigidities and the business cycle. Review of Economic Dynamics 14(2), 225-247.

An, S. and F. Schorfheide (2007) Bayesian analysis of DSGE models. Econometric Reviews 26(2-4), 113-172.

Backus, D., P. Kehoe, and F.E. Kydland (1995) International business cycles: Theory and evidence. In T. Cooley (ed.), Frontiers of Business Cycle Research, pp. 331-356. Princeton, NJ: Princeton University Press.

Backus, D. and G.W. Smith (1993) Consumption and real exchange rates in dynamic economies with non-traded goods. Journal of International Economics 35, 297-316.

Basu, P. and C. Thoenissen (2011) International business cycles and the relative price of investment goods. Canadian Journal of Economics 44(2), 580-606.

Baxter, M. and M.J. Crucini (1995) Business cycles and the asset structure of foreign trade. International Economic Review 36(4).

Bernanke, B., M. Gertler, and S. Gilchrist (1999) The financial accelerator in a quantitative business cycle framework. In J.B. Taylor and M. Woodford (eds.), Handbook of Macroeconomics, 1st ed., Vol. 1, Chap. 21, pp. 1341-1393.

Carlstrom, C. and T. Fuerst (1997) Agency costs, net worth, and business fluctuations: A computable general equilibrium analysis. American Economic Review 87, 893-910. 
Christiano, L., M. Eichenbaum, and C. Evans (2005) Nominal rigidities and the dynamic effects of a shock to monetary policy. Journal of Political Economy 113(1), 1-45.

Christiano, L., C. Ilut, R. Motto, and M. Rostagno (2008) Monetary Policy and a Stock Market Boom-Bust Cycle. Working paper 0955, European Central Bank.

Christoffel, K., Coenen, G., and A. Warne (2008) The New Area-Wide Model of the Euro Area: A Micro-Founded Open-Economy Model for Forecasting and Policy Analysis. ECB working paper 944.

Corsetti, G., L. Dedola, and S. Leduc (2008) International risk sharing and the transmission of productivity shocks. Review of Economic Studies 75, 443-473.

de Walque, G., F. Smets, and R. Wouters (2005) An Estimated Two-Country DSGE Model for the Euro Area and the US Economy. Working paper, National Bank of Belgium.

Enders, Z. and G.J. Muller (2009) On the international transmission of technology shocks. Journal of International Economics 78(1), 45-59.

Fernández-Villaverde, J. and J.F. Rubio-Ramírez (2004) Comparing dynamic equilibrium models to data: A Bayesian approach. Journal of Econometrics 123, 153-187.

Fisher, J.D.M. (2006) The dynamic effects of neutral and investment-specific technology shocks. Journal of Political Economy 114(3), 413-451.

Gali, J. (1999) Technology, employment, and the business cycle: Do technology shocks explain aggregate fluctuations? American Economic Review 89(1), 249-271.

Greenwood, J., Z. Hercowitz, and G.W. Huffman (1988) Investment, capacity utilization and the real business cycle. American Economic Review 78, 402-417.

Greenwood, J., Z. Hercowitz, and P. Krusell (1997) Long-run implications of investment-specific technological change. American Economic Review 87(June), 342-362.

Heathcote, J. and F. Perri (2002) Financial autarky and international business cycles. Journal of Monetary Economics 49, 601-627.

Heathcote, J. and F. Perri (2013) The international diversification puzzle is not as bad as you think. Journal of Political Economy 121(6), 1108-1159.

Ireland, P. (2013) Stochastic growth in the United States and Euro Area. Journal of the European Economic Association 11(1), 1-24.

Jacob, P. and G. Peersman (2013) Dissecting the dynamics of the US trade balance in an estimated equilibrium model. Journal of International Economics, 90(2), pp. 302-315.

Justiniano, A. and B. Preston (2010) Can structural small open economy models account for the influence of foreign disturbances? Journal of International Economics 81, 61-74.

Justiniano, A., G. Primiceri, and A. Tambalotti (2010) Investment shocks and business cycles. Journal of Monetary Economics 57(2), 132-145.

Justiniano, A., G. Primiceri, and A. Tambalotti (2011) Investment shocks and the relative price of investment. Review of Economic Dynamics 14(1), 101-121.

King, R.G., C.I. Plosser, J.H. Stock, and M.W. Watson (1991) Stochastic trends and economic fluctuations. American Economic Review 81(4), 819-840.

Kollmann, R. (2013) Global banks, financial shocks and international business cycles: Evidence from an estimated model. Journal of Money, Credit and Banking 45(2), 159-195.

Komunjer, I. and S. Ng (2011) Dynamic identification of DSGE models. Econometrica 79(6), 19952032.

Lubik, T.A. and F. Schorfheide (2006) A Bayesian look at new open economy macroeconomics. In G. Mark and K. Rogoff (eds.), NBER Macroeconomics Annual 2005, pp. 313-366. Cambridge, MA: MIT Press.

Mandelman, F., P. Rabanal, J.F. Rubio-Ramírez, and D. Vilán (2011) Investment-specific technology shocks and international business cycles: An empirical assessment. Review of Economic Dynamics 14(1), 136-155.

Obstfeld, M. and K. Rogoff (2000) The six major puzzles in international macroeconomics: Is there a common cause? In Ben S. Bernanke and Kenneth Rogoff (eds.), NBER Macroeconomics Annual, 2000. Cambridge, MA: MIT Press. 
Rabanal, P. and V. Tuesta (2010) Euro-dollar real exchange rate dynamics in an estimated two-country model: An assessment. Journal of Economic Dynamics and Control 34, 780-797.

Raffo, A. (2007) Net exports, consumption volatility and international business cycle models. Journal of International Economics 75, 14-29.

Raffo, A. (2010) Technology Shocks: Novel Implications for International Business Cycles. International finance discussion paper 992, Board of Governors of the Federal Reserve System (U.S.).

Schmitt-Grohé, S. and M. Uribe (2012) What's news in business cycles. Econometrica 80, 2733-2764.

Smets, F. and R. Wouters (2003) An estimated dynamic stochastic general equilibrium model of the Euro area. Journal of European Economic Association 1(5), 1123-1175.

Smets, F. and R. Wouters (2007) Shocks and frictions in US business cycles: A Bayesian approach. American Economic Review 97(3), 586-606.

\section{APPENDIX A: BENCHMARK WITH COMPLETE MARKETS}

\section{A.1. OPTIMALITY CONDITIONS}

Because the model contains nonstationary worldwide technology shocks, I detrend the affected variables in both the countries, i.e., output, consumption, investment, and real wages, by the level of world technology $Z_{t-1}$ and capital by $Z_{t-1} V_{t-1}$, where $Z_{t-1}=$ $A_{t-1}^{1 /(1-\alpha)} V_{t-1}^{\alpha /(1-\alpha)}$. Other variables such as labor hours, capital utilization rate, prices, real exchange rate, and terms of trade are assumed to be stationary. Let us denote the detrended variables in lower case. To understand the channels better, let us look at the first-order conditions for this economy:

- Final goods problem:

$$
\operatorname{Max}_{a_{i t}, b_{i t}} G_{i}\left(a_{i t}, b_{i t}\right)-q_{i t}^{a} a_{i t}-q_{i t}^{b} b_{i t} .
$$

First-order conditions:

$$
\begin{aligned}
& {\left[a_{i t}\right]: G_{a_{i t}}-q_{i t}^{a}=0,} \\
& {\left[b_{i t}\right]: G_{b_{i t}}-q_{i t}^{b}=0 .}
\end{aligned}
$$

- Household problem for country H:

$$
\operatorname{Max} \sum_{t=0}^{\infty} \beta^{t} U\left(c_{\mathrm{H}, t}, 1-l_{\mathrm{H}, t}\right),
$$

subject to

$$
\begin{aligned}
& q_{\mathrm{H}, t}^{a}\left(W_{\mathrm{H}, t} l_{\mathrm{H}, t}+R_{\mathrm{H}, t} h_{\mathrm{H}, t} K_{\mathrm{H}, \mathrm{t}}\right)+q_{\mathrm{H}, t}^{a} B_{\mathrm{H}, t-1}=C_{\mathrm{H}, t}+I_{\mathrm{H}, t}+q_{\mathrm{H}, t}^{a} \sum_{s_{t+1}} Q_{t-1, t} B_{\mathrm{H}, t}, \\
& K_{\mathrm{H}, t}=\left(1-\delta\left(h_{\mathrm{H}, t}\right)\right) K_{\mathrm{H}, t-1} \\
& \quad+v_{\mathrm{H}, t} V_{t}\left[I_{\mathrm{H}, t}-\frac{\phi}{2} I_{\mathrm{H}, t-1} \frac{V_{t-1}}{V_{t}}\left(\frac{I_{\mathrm{H}, t} V_{t}}{I_{\mathrm{H}, t-1} V_{t-1}}-\Lambda_{x}\right)^{2}\right]
\end{aligned}
$$


Let $\lambda_{\mathrm{H}}^{1}, \lambda_{\mathrm{H}}^{2}$ be Langrangian multipliers for constraints (A.3), (A.4), respectively. The first-order conditions after detrending are

$$
\begin{gathered}
\frac{g_{\mathrm{H}, t}}{\left(c_{\mathrm{H}, t}-\psi l_{\mathrm{H}, t}^{\tau}\right)^{\sigma_{c}}}=\Lambda_{\mathrm{H}, t}^{1}, \\
\frac{g_{\mathrm{H}, t}}{\left(c_{\mathrm{H}, t}-\psi l_{\mathrm{H}, t}^{\tau}\right)^{\sigma_{c}}} \psi \tau l_{\mathrm{H}, t}^{\tau-1}=\Lambda_{\mathrm{H}, t}^{1} w_{\mathrm{H}, t} q_{\mathrm{H}, t}^{a}, \\
g_{\mathrm{Zt}}^{\sigma_{c}} g_{V t} \Lambda_{\mathrm{H}, t}^{2}=\beta E_{t}\left[\Lambda_{\mathrm{H}, t+1}^{1} q_{\mathrm{H}, t+1}^{a} r_{\mathrm{H}, t+1} h_{\mathrm{H}, t+1}+\lambda_{\mathrm{H}, t+1}^{2}\left(1-\kappa \frac{h_{\mathrm{H}, t+1}^{\sigma_{u}+1}}{\sigma_{u}+1}\right)\right], \\
\Lambda_{\mathrm{H}, t}^{1}=\Lambda_{\mathrm{H}, t}^{2} v_{\mathrm{H}, t} g_{V t}\left(1-\phi\left(\frac{i_{\mathrm{H}, t}}{i_{\mathrm{H}, t-1}} g_{\mathrm{Z} t-1} g_{V t}-\Lambda_{x}\right)\right) \\
+\beta E_{t} \Lambda_{\mathrm{H}, t+1}^{2} v_{\mathrm{H}, t+1} g_{\mathrm{Zt}}^{-\sigma_{c}} g_{V t+1} \\
\times\left[\frac{i_{\mathrm{H}, t+1}}{i_{\mathrm{H}, t}} g_{\mathrm{Z} t} g_{V t+1}-\Lambda_{x}\right) \frac{i_{\mathrm{H}, t+1}}{i_{\mathrm{H}, t}} g_{\mathrm{Z} t} \\
\left.\phi \frac{\phi}{2 g_{V t+1}}\left(\frac{i_{\mathrm{H}, t+1}}{i_{\mathrm{H}, t}} g_{Z t} g_{V t+1}-\Lambda_{x}\right)^{2}\right], \\
\Lambda_{\mathrm{H}, t}^{1} q_{\mathrm{H}, t}^{a} r_{\mathrm{H}, t}=\Lambda_{\mathrm{H}, t}^{2} h_{H}^{\sigma_{u}}, \\
\Lambda_{\mathrm{H}, t}^{1} Q(t, t+1) q_{\mathrm{H}, t}^{a}=\beta E_{t} \Lambda_{\mathrm{H}, t+1}^{1} g_{\mathrm{Zt}}^{-\sigma_{c}} q_{\mathrm{H}, t+1}^{a},
\end{gathered}
$$

where $c_{t}=\frac{C_{t}}{Z_{t-1}}, i_{t}=\frac{I_{t}}{Z_{t-1}}, k_{t-1}=\frac{K_{t-1}}{Z_{t-1} V_{t-1}}, r_{t}=R_{t} V_{t-1}, w_{t}=\frac{W_{t}}{Z_{t-1}}, \Lambda_{t}^{1}=$ $\lambda_{t}^{1} Z_{t-1}^{\sigma_{c}}, \Lambda_{t}^{2}=\lambda_{t}^{2} Z_{t-1}^{\sigma_{c}} V_{t-1}, g_{Z, t}=\frac{Z_{t}}{Z_{t-1}}, g_{V, t}=\frac{V_{t}}{V_{t-1}}$, and $g_{A, t}=\frac{A_{t}}{A_{t-1}}$.

- Household problem in country 2 :

$$
\operatorname{Max} \sum_{t=0}^{\infty} \beta^{t} U\left(c_{\mathrm{F}, t}, 1-l_{\mathrm{F}, t}\right),
$$

subject to

$$
\begin{aligned}
& q_{\mathrm{F}, t}^{b}(\left.W_{\mathrm{F}, t} l_{\mathrm{F}, t}+R_{\mathrm{F}, t} h_{\mathrm{F}, t} K_{\mathrm{F}, t}\right)+q_{\mathrm{F}, t}^{a} B_{\mathrm{F}, t-1}=C_{\mathrm{F}, t}+I_{\mathrm{F}, t}+q_{\mathrm{F}, t}^{a} \sum_{s_{t+1}} Q_{t-1, t} B_{\mathrm{F}, t}, \\
& K_{\mathrm{F}, t}=\left(1-\delta\left(h_{\mathrm{F}, t}\right)\right) K_{\mathrm{F}, t-1} \\
&+v_{\mathrm{F}, t} V_{t}\left[I_{\mathrm{F}, t}-\frac{\phi}{2} I_{\mathrm{F}, t-1} \frac{V_{t-1}}{V_{t}}\left(\frac{I_{\mathrm{F}, t} V_{t}}{I_{\mathrm{F}, t-1} V_{t-1}}-\Lambda_{x}\right)^{2}\right] .
\end{aligned}
$$

Let $\lambda_{\mathrm{F}}^{1}, \lambda_{\mathrm{F}}^{2}$ be Langrangian multipliers for constraints (A.11), (A.12), respectively. The first-order conditions after detrending are

$$
\frac{g_{\mathrm{F}, t}}{\left(c_{\mathrm{F}, t}-\psi l_{\mathrm{F}, t}^{\tau}\right)^{\sigma_{c}}}=\Lambda_{\mathrm{F}, t}^{1}
$$




$$
\begin{gathered}
\frac{g_{\mathrm{F}, t}}{\left(c_{\mathrm{F}, t}-\psi l_{\mathrm{F}, t}^{\tau}\right)^{\sigma_{c}}} \psi \tau l_{\mathrm{F}, t}^{\tau-1}=\Lambda_{\mathrm{F}, t}^{1} w_{\mathrm{F}, t} q_{\mathrm{F}, t}^{b}, \\
g_{Z t}^{\sigma_{c}} g_{V t} \Lambda_{\mathrm{F}, t}^{2}=\beta E_{t}\left[\Lambda_{\mathrm{F}, t+1}^{1} q_{\mathrm{F}, t+1}^{b} r_{\mathrm{F}, t+1} h_{\mathrm{F}, t+1}+\lambda_{\mathrm{F}, t+1}^{2}\left(1-\kappa \frac{h_{\mathrm{F}, t+1}^{\sigma_{u}+1}}{\sigma_{u}+1}\right)\right] \\
\Lambda_{\mathrm{F}, t}^{1}=\Lambda_{\mathrm{F}, t}^{2} v_{\mathrm{F}, t} g_{V t}\left(1-\phi\left(\frac{i_{\mathrm{F}, t}}{i_{\mathrm{F}, t-1}} g_{Z t-1} g_{V t}-\Lambda_{x}\right)\right) \\
+\beta E_{t} \Lambda_{\mathrm{F}, t+1}^{2} v_{\mathrm{F}, t+1} g_{\mathrm{Z} t}^{-\sigma_{c}} g_{V t+1} \\
\times\left[\phi\left(\frac{i_{\mathrm{F}, t+1}}{i_{\mathrm{F}, t}} g_{Z t} g_{V t+1}-\Lambda_{x}\right) \frac{i_{\mathrm{F}, t+1}}{i_{\mathrm{F}, t}} g_{\mathrm{Z} t}\right. \\
\left.-\frac{\phi}{2 g_{V t+1}}\left(\frac{i_{\mathrm{F}, t+1}}{i_{\mathrm{F}, t}} g_{Z t} g_{V t+1}-\Lambda_{x}\right)^{2}\right] \\
\Lambda_{\mathrm{F}, t}^{1} q_{\mathrm{F}, t}^{b} r_{\mathrm{F}, t}=\Lambda_{\mathrm{F}, t}^{2} h_{\mathrm{F}, t}^{\sigma_{u}}, \\
\Lambda_{\mathrm{F}, t}^{1} Q(t, t+1) q_{\mathrm{F}, t}^{a}=\beta E_{t} \Lambda_{\mathrm{F}, t+1}^{1} g_{\mathrm{Z} t}^{-\sigma_{c}} q_{\mathrm{F}, t+1}^{a} .
\end{gathered}
$$

- Intermediate goods problem:

$$
\operatorname{Max}_{K_{i t} \geq 0, l_{i t} \geq 0} F\left(z_{i t}, A_{t}, K_{i t}, h_{i t}, l_{i t}\right)-W_{i t} l_{i t}-R_{i t} K_{i t} h_{i t},
$$

subject to

$$
F\left(z_{i t}, A_{t}, K_{i t}, h_{i t}, l_{i t}\right)=z_{i t} A_{t}\left(K_{i t-1} h_{i t}\right)^{\alpha}\left(l_{i t}\right)^{(1-\alpha)} .
$$

First-order conditions:

$$
\begin{gathered}
r_{i t}=z_{i t} g_{A t} \alpha\left(h_{i t} k_{i t-1}\right)^{(\alpha-1)} l_{i t}^{(1-\alpha)}, \\
w_{i t}=z_{i t} g_{A t}(1-\alpha)\left(h_{i t} k_{i t-1}\right)^{\alpha} l_{i t}^{(-\alpha)} .
\end{gathered}
$$

From (A.10) and (A.18), I obtain the following relationship for the real exchange rate:

$$
\frac{\Lambda_{\mathrm{F}, t+1}}{\Lambda_{\mathrm{H}, t+1}} \frac{q_{\mathrm{F}, t+1}^{a}}{q_{\mathrm{H}, t+1}^{a}}=\frac{\Lambda_{\mathrm{F}, t}}{\Lambda_{\mathrm{H}, t}} \frac{q_{\mathrm{F}, t}^{a}}{q_{\mathrm{H}, t}^{a}} .
$$

Iterating this equation, I obtain

$$
\frac{\Lambda_{\mathrm{F}, t}}{\Lambda_{\mathrm{H}, t}}=c \cdot \frac{q_{\mathrm{H}, t}^{a}}{q_{\mathrm{F}, t}^{a}}=c \cdot \text { rer, }
$$

where $c=\frac{\Lambda_{20}}{\Lambda_{10}} \frac{q_{20}^{a}}{q_{10}^{a}}$. 
Log-linearized equations:

- Consumption Euler equations:

$$
\begin{aligned}
& \frac{1}{\left(\bar{c}-\psi \bar{l}^{\tau}\right)^{\sigma_{c}}}\left[\bar{c} \hat{c}_{\mathrm{H}, t}-\psi \tau \bar{l}^{\tau} \hat{l}_{\mathrm{H}, t}\right]=-\frac{1}{\sigma_{c}}\left[\hat{\Lambda}_{\mathrm{H}, t}^{1}-\hat{g}_{\mathrm{H}, t}\right], \\
& \frac{1}{\left(\bar{c}-\psi \bar{l}^{\tau}\right)^{\sigma_{c}}}\left[\bar{c} \hat{c}_{\mathrm{F}, t}-\psi \tau \bar{l}^{\tau} \hat{l}_{\mathrm{F}, t}\right]=-\frac{1}{\sigma_{c}}\left[\hat{\Lambda}_{\mathrm{F}, t}^{1}-\hat{g}_{\mathrm{F}, t}\right] .
\end{aligned}
$$

- Labor supply:

$$
\begin{aligned}
& (\tau-1) \hat{l}_{\mathrm{H}, t}=\hat{w}_{\mathrm{H}, t}+\hat{q}_{\mathrm{H}, t}^{a}, \\
& (\tau-1) \hat{l}_{\mathrm{F}, t}=\hat{w}_{\mathrm{F}, t}+\hat{q}_{\mathrm{F}, t}^{b} .
\end{aligned}
$$

- Capital Euler equations:

$$
\begin{aligned}
& \hat{\Lambda}_{\mathrm{H}, t}^{2}=\frac{\beta}{g_{Z}^{\sigma_{c}} g_{v}} E_{t}\left[(1-\delta) \hat{\Lambda}_{\mathrm{H}, t+1}^{2}+\left(\frac{g_{Z}^{\sigma_{c}} g_{v}}{\beta}-1+\delta\right)\left(\hat{\Lambda}_{\mathrm{H}, t+1}^{1}+\hat{r}_{\mathrm{H}, t+1}+\hat{q}_{\mathrm{H}, t+1}^{a}\right)\right] \\
& -\sigma_{c} \hat{g}_{Z t}-\hat{g}_{V t}, \\
& \hat{\Lambda}_{\mathrm{F}, t}^{2}=\frac{\beta}{g_{Z}^{\sigma_{c}} g_{v}} E_{t}\left[(1-\delta) \hat{\Lambda}_{\mathrm{F}, t+1}^{2}+\left(\frac{g_{Z}^{\sigma_{c}} g_{v}}{\beta}-1+\delta\right)\left(\hat{\Lambda}_{\mathrm{F}, t+1}^{1}+\hat{r}_{\mathrm{F}, t+1}+\hat{q}_{F, t+1}^{b}\right)\right] \\
& \quad-\sigma_{c} \hat{g}_{Z t}-\hat{g}_{V t t} .
\end{aligned}
$$

- Investment Euler equations:

$$
\begin{aligned}
& \Lambda_{\mathrm{H}, t}^{1}=\Lambda_{\mathrm{H}, t}^{2}+\hat{v}_{\mathrm{H}, t}+\hat{g}_{V t}-\phi g_{z} g_{v}\left(\hat{i}_{\mathrm{H}, t}-\hat{i}_{\mathrm{H}, t-1}+\hat{g}_{V t}+\hat{g}_{Z t-1}\right) \\
& \quad+\beta \phi g_{z}^{2-\sigma_{c}} g_{v}^{2} E_{t}\left(\hat{i}_{\mathrm{H}, t+1}-\hat{i}_{\mathrm{H}, t}+\hat{g}_{V t+1}+\hat{g}_{Z t}\right) \\
& \Lambda_{\mathrm{F}, t}^{1}=\Lambda_{\mathrm{F}, t}^{2}+\hat{v}_{\mathrm{F}, t}+\hat{g}_{V t}-\phi g_{z} g_{v}\left(\hat{i}_{\mathrm{F}, t}-\hat{i}_{\mathrm{F}, t-1}+\hat{g}_{V t}+\hat{g}_{Z t-1}\right) \\
& \quad+\beta \phi g_{z}^{2-\sigma_{c}} g_{v}^{2} E_{t}\left(\hat{i}_{\mathrm{F}, t+1}-\hat{i}_{\mathrm{F}, t}+\hat{g}_{V t+1}+\hat{g}_{Z t}\right) .
\end{aligned}
$$

- Capital utilization Euler equations:

$$
\begin{gathered}
\hat{\Lambda}_{\mathrm{H}, t}^{1}+\hat{r}_{\mathrm{H}, t}+\hat{q}_{\mathrm{H}, t}^{a}=\hat{\Lambda}_{\mathrm{H}, t}^{2}+\sigma_{u} \hat{h}_{\mathrm{H}, t}, \\
\hat{\Lambda}_{\mathrm{F}, t}^{1}+\hat{r}_{\mathrm{F}, t}+\hat{q}_{\mathrm{F}, t}^{b}=\hat{\Lambda}_{\mathrm{F}, t}^{2}+\sigma_{u} \hat{h}_{\mathrm{F}, t} .
\end{gathered}
$$

- Capital accumulation equations:

$$
\begin{aligned}
\hat{k}_{\mathrm{H}, t} & =\frac{(1-\delta)}{g_{Z} g_{V}}\left(\hat{k}_{\mathrm{H}, t-1}-\hat{g}_{Z t}-\hat{g}_{V t}\right)-\frac{\kappa}{g_{Z} g_{V}} \bar{h}^{\left(\sigma_{u}+1\right)} \hat{h}_{\mathrm{H}, t} \\
+ & \left(1-\frac{(1-\delta)}{g_{Z} g_{V}}\right)\left(\hat{i}_{\mathrm{H}, t}-\hat{g}_{Z t}+\hat{v}_{\mathrm{H}, t}\right),
\end{aligned}
$$




$$
\begin{aligned}
\hat{k}_{\mathrm{F}, t} & =\frac{(1-\delta)}{g_{Z} g_{V}}\left(\hat{k}_{\mathrm{F}, t-1}-\hat{g}_{Z t}-\hat{g}_{V t}\right)-\frac{\kappa}{g_{Z} g_{V}} \bar{h}^{\left(\sigma_{u}+1\right)} \hat{h}_{\mathrm{F}, t} \\
+ & \left(1-\frac{(1-\delta)}{g_{Z} g_{V}}\right)\left(\hat{i}_{\mathrm{F}, t}-\hat{g}_{Z t}+\hat{v}_{\mathrm{F}, t}\right) .
\end{aligned}
$$

- Labor demand:

$$
\begin{gathered}
\hat{w}_{\mathrm{H}, t}=\hat{z}_{\mathrm{H}, t}+\hat{g}_{A t}+\alpha\left(\hat{k}_{\mathrm{H}, t-1}+\hat{h}_{\mathrm{H}, t}\right)-\alpha \hat{l}_{\mathrm{H}, t}, \\
\hat{w}_{\mathrm{F}, t}=\hat{z}_{\mathrm{F}, t}+\hat{g}_{A t}+\alpha\left(\hat{k}_{\mathrm{F}, t-1}+\hat{h}_{\mathrm{F}, t}\right)-\alpha \hat{l}_{\mathrm{F}, t} .
\end{gathered}
$$

- Capital demand:

$$
\begin{aligned}
& \hat{r}_{\mathrm{H}, t}=\hat{z}_{\mathrm{H}, t}+\hat{g}_{A t}+(\alpha-1)\left(\hat{k}_{\mathrm{H}, t-1}+\hat{h}_{\mathrm{H}, t}\right)+(1-\alpha) \hat{l}_{\mathrm{H}, t}, \\
& \hat{r}_{\mathrm{F}, t}=\hat{z}_{\mathrm{F}, t}+\hat{g}_{A t}+(\alpha-1)\left(\hat{k}_{\mathrm{F}, t-1}+\hat{h}_{\mathrm{F}, t}\right)+(1-\alpha) \hat{l}_{\mathrm{F}, t} .
\end{aligned}
$$

- Demand for intermediate goods:

$$
\begin{aligned}
& \hat{a}_{\mathrm{H}, t}=\hat{G}_{\mathrm{H}, t}-\theta \hat{q}_{\mathrm{H}, t}^{a}, \\
& \hat{b}_{\mathrm{H}, t}=\hat{G}_{\mathrm{H}, t}-\theta \hat{q}_{\mathrm{H}, t}^{b}, \\
& \hat{a}_{\mathrm{F}, t}=\hat{G}_{\mathrm{F}, t}-\theta \hat{q}_{\mathrm{F}, t}^{a}, \\
& \hat{b}_{\mathrm{F}, t}=\hat{G}_{\mathrm{F}, t}-\theta \hat{q}_{\mathrm{F}, t}^{b} .
\end{aligned}
$$

- Production functions:

$$
\begin{aligned}
& \hat{G}_{\mathrm{H}, t}=\omega \hat{a}_{\mathrm{H}, t}+(1-\omega) \hat{b}_{\mathrm{H}, t}, \\
& \hat{G}_{\mathrm{F}, t}=\omega \hat{b}_{\mathrm{F}, t}+(1-\omega) \hat{a}_{\mathrm{F}, t} . \\
& \operatorname{gd} \hat{\mathrm{H}}_{\mathrm{H}, t}=\hat{z}_{\mathrm{H}, t}+\hat{g}_{A t}+(\alpha)\left(\hat{k}_{\mathrm{H}, t-1}+\hat{h}_{\mathrm{H}, t}\right)+(1-\alpha) \hat{l}_{\mathrm{H}, t} \text {, } \\
& \operatorname{gd} \hat{\mathrm{p}}_{\mathrm{F}, t}=\hat{z}_{\mathrm{F}, t}+\hat{g}_{A t}+(\alpha)\left(\hat{k}_{\mathrm{F}, t-1}+\hat{h}_{\mathrm{F}, t}\right)+(1-\alpha) \hat{l}_{\mathrm{F}, t}
\end{aligned}
$$

- Market clearing:

$$
\begin{aligned}
\operatorname{gad} \hat{\mathrm{H}}_{, t} & =\omega \hat{a}_{\mathrm{H}, t}+(1-\omega) \hat{a}_{\mathrm{F}, t}, \\
\operatorname{gd} \mathrm{p}_{\mathrm{F}, t} & =\omega \hat{b}_{\mathrm{F}, t}+(1-\omega) \hat{b}_{\mathrm{H}, t}, \\
\hat{G}_{\mathrm{H}, t} & =\frac{\bar{c}}{\operatorname{gdp}} \hat{c}_{\mathrm{H}, t}+\frac{\bar{c}}{\operatorname{gd}} \hat{i}_{\mathrm{H}, t}, \\
\hat{G}_{\mathrm{F}, t} & =\frac{\bar{c}}{\operatorname{gd} \bar{p}} \hat{c}_{\mathrm{F}, t}+\frac{\bar{c}}{\operatorname{gd} \overline{\mathrm{d}}} \hat{i}_{\mathrm{F}, t} .
\end{aligned}
$$

- Law of one price:

$$
\begin{aligned}
& \hat{q}_{\mathrm{H}, t}^{a}=\operatorname{rê}_{t}+\hat{q}_{\mathrm{F}, t}^{a}, \\
& \hat{q}_{\mathrm{H}, t}^{b}=\operatorname{rêr}_{t}+\hat{q}_{\mathrm{F}, t}^{b} .
\end{aligned}
$$


- Shock processes:

$$
\hat{g}_{Z t}=\frac{1}{(1-\alpha)} \hat{g}_{A t}+\frac{\alpha}{(1-\alpha)} \hat{g}_{V t},
$$

where $\hat{g}_{A t}=\epsilon_{t}^{A}$ and $\hat{g}_{V t}=\epsilon_{t}^{V}$,

$$
\begin{aligned}
& \hat{z}_{i t}=\rho_{i}^{z} \hat{z}_{i t-1}+\epsilon_{i t}^{z}, \\
& \hat{g}_{i t}=\rho_{i}^{g} \hat{g}_{i t-1}+\epsilon_{i t}^{g}, \\
& \hat{v}_{i t}=\rho_{i}^{v} \hat{v}_{i t-1}+\epsilon_{i t}^{v} .
\end{aligned}
$$

\section{A.2. LOG-LINEARIZED EXPRESSIONS FOR REAL EXCHANGE RATE AND TERMS OF TRADE}

Real exchange rate:

$$
\operatorname{rêr}_{t}=\hat{\Lambda}_{\mathrm{F}, t}-\hat{\Lambda}_{\mathrm{H}, t} \text {. }
$$

Substituting for $\hat{\Lambda}_{\mathrm{H}, t}, \hat{\Lambda}_{\mathrm{F}, t}$ from equations (A.24) and (A.25) gives

$$
\text { rêr }=\left[\alpha_{c}\left(\hat{c}_{\mathrm{H}, t}-\hat{c}_{\mathrm{F}, t}\right)-\alpha_{l}\left(\hat{l}_{\mathrm{H}, t}-\hat{l}_{\mathrm{F}, t}\right)-\left(\hat{g}_{\mathrm{H}, t}-\hat{g}_{\mathrm{F}, t}\right)\right] \text {, }
$$

where

$$
\begin{aligned}
\alpha_{c} & =\sigma_{c} \frac{\bar{c}}{\bar{c}-\psi \bar{l}^{\tau}}, \\
\alpha_{l} & =\sigma_{c} \frac{\psi \tau \bar{l}^{\tau}}{\bar{c}-\psi \bar{l}^{\tau}} .
\end{aligned}
$$

Terms of trade:

First I substitute the expressions for domestic absorption (A.44) and (A.45) into equations (A.40), (A.41), (A.42), and (A.43) to get the following expressions:

$$
\begin{gathered}
\theta \hat{q}_{\mathrm{H}, t}^{a}=(1-\omega)\left(\hat{b}_{\mathrm{H}, t}-\hat{a}_{\mathrm{H}, t}\right), \\
\theta \hat{q}_{\mathrm{H}, t}^{b}=-\omega\left(\hat{b}_{\mathrm{H}, t}-\hat{a}_{\mathrm{H}, t}\right)=\theta\left(\mathrm{rêr}_{t}+\hat{q}_{\mathrm{F}, t}^{b}\right), \\
\theta \hat{q}_{\mathrm{F}, t}^{a}=\omega\left(\hat{b}_{\mathrm{F}, t}-\hat{a}_{\mathrm{F}, t}\right)=\theta\left(\hat{q}_{\mathrm{H}, t}^{a}-\text { rêr }_{t}\right), \\
\theta \hat{q}_{\mathrm{F}, t}^{b}=-(1-\omega)\left(\hat{b}_{\mathrm{F}, t}-\hat{a}_{\mathrm{F}, t}\right) .
\end{gathered}
$$

Combining equations (A.60) and (A.61), and (A.62) and (A.63),

$$
\begin{gathered}
\left(\text { rêr }_{t}+\hat{q}_{\mathrm{F}, t}^{b}\right)=-\frac{\omega}{(1-\omega)} \hat{q}_{\mathrm{H}, t}^{a}, \\
\left(\text { rêr }_{t}-\hat{q}_{\mathrm{H}, t}^{a}\right)=\frac{\omega}{(1-\omega)} \hat{q}_{\mathrm{F}, t}^{b} .
\end{gathered}
$$

Substituting $\hat{q}_{\mathrm{F}, t}^{b}$ from (A.65) into (A.64) and simplifying,

$$
\hat{q}_{\mathrm{H}, t}^{a}=\frac{(\omega-1)}{(2 \omega-1)} \text { rêr }_{t}
$$


and

$$
\hat{q}_{\mathrm{F}, t}^{b}=\frac{(1-\omega)}{(2 \omega-1)} \mathrm{rê}_{t}
$$

By definition,

$$
\text { tôt }_{t}=\hat{q}_{\mathrm{H}, t}^{b}-\hat{q}_{\mathrm{H}, t}^{a}=\operatorname{rêr}_{t}+\hat{q}_{\mathrm{F}, t}^{b}-\hat{q}_{\mathrm{H}, t}^{a} .
$$

Substituting (A.66) and (A.67) into equation (A.68),

$$
\text { tôt }_{t}=\frac{1}{(2 \omega-1)} \text { rêr }_{t} \text {. }
$$

Furthermore, combining equations (A.60) and (A.66), and (A.63) and (A.2.67),

$$
\begin{aligned}
& \left(\hat{b}_{\mathrm{H}, t}-\hat{a}_{\mathrm{H}, t}\right)=-\frac{\theta}{(2 \omega-1)} \operatorname{rêr}_{t}, \\
& \left(\hat{b}_{\mathrm{F}, t}-\hat{a}_{\mathrm{F}, t}\right)=-\frac{\theta}{(2 \omega-1)} \operatorname{rêr}_{t} .
\end{aligned}
$$

Using (A.48), (A.49), and (A.71), equation (A.70) becomes

$$
\hat{b}_{\mathrm{H}, t}=-\theta \frac{\omega}{(2 \omega-1)^{2}} \text { rêr }_{t}+\frac{1}{(2 \omega-1)}\left(\omega \mathrm{gd} \hat{p}_{\mathrm{H}, t}-(1-\omega) \operatorname{gdp} \mathrm{p}_{\mathrm{F}, t}\right) .
$$

Similarly, combining equations (A.49), (A.70), and (A.72),

$$
\hat{a}_{\mathrm{F}, t}=\theta \frac{\omega}{(2 \omega-1)^{2}} \text { rêr }_{t}+\frac{1}{(2 \omega-1)}\left(\omega \mathrm{gd} \hat{p}_{\mathrm{F}, t}-(1-\omega) \operatorname{gd} \mathrm{p}_{\mathrm{H}, t}\right) .
$$

By definition,

$$
\frac{\mathrm{nx}}{y}=(1-\omega)\left(\hat{a}_{\mathrm{F}, t}-\hat{b}_{\mathrm{H}, t}-\mathrm{tôt}_{t}\right)
$$

Using equations (A.67), (A.72), and (A.73) and simplifying,

$$
\text { tôt }_{t}=d_{1} d_{2} \frac{\mathrm{nx}}{y}+d_{1}\left(\mathrm{gâp}_{\mathrm{H}, t}-\mathrm{gâp}_{\mathrm{F}, t}\right),
$$

where $d_{1}=\frac{1}{2 \omega(\theta-1)+1}, d_{2}=\frac{2 \omega-1}{1-\omega}$.

\section{APPENDIX B: INCOMPLETE MARKET MODEL}

Under incomplete markets, the budget constraints in home and foreign countries are given by

$$
\begin{gathered}
q_{\mathrm{H}, t}^{a}\left(W_{\mathrm{H}, t} l_{\mathrm{H}, t}+R_{\mathrm{H}, t} h_{\mathrm{H}, t} K_{\mathrm{H}, t}\right)+q_{\mathrm{H}, t}^{a} B_{\mathrm{H}, t-1}=C_{\mathrm{H}, t}+I_{\mathrm{H}, t}+q_{\mathrm{H}, t}^{a}\left[Q_{t} B_{\mathrm{H}, t}-\phi_{1}\left(B_{\mathrm{H}, t}\right)\right], \\
q_{\mathrm{F}, t}^{b}\left(W_{\mathrm{F}, t} l_{\mathrm{F}, t}+R_{\mathrm{F}, t} h_{\mathrm{F}, t} K_{\mathrm{F}, t}\right)+q_{\mathrm{F}, t}^{a} B_{\mathrm{F}, t-1}=C_{\mathrm{F}, t}+I_{\mathrm{F}, t}+q_{\mathrm{F}, t}^{a} Q_{t} B_{\mathrm{F}, t},
\end{gathered}
$$


where $\phi_{1}\left(B_{\mathrm{H}, t}\right)=\frac{\psi_{1}}{2} Z_{t-1}\left(\frac{B_{\mathrm{H}, t}}{Z_{t-1}}\right)^{2}$. The bond market clearing condition becomes

$$
B_{\mathrm{H}, t}+B_{\mathrm{F}, t}=0
$$

Optimality conditions imply the following (detrended) bond Euler equations:

$$
\begin{gathered}
Q_{t}=\beta E_{t}\left[\frac{\Lambda_{\mathrm{H}, t+1}^{1}}{\Lambda_{\mathrm{H}, t}^{1}} g_{\mathrm{Z} t}^{-\sigma_{c}} \frac{q_{\mathrm{H}, t+1}^{a}}{q_{\mathrm{H}, t}^{a}}\right]-\psi_{1} b_{\mathrm{H}, t}, \\
Q_{t}=\beta E_{t}\left[\frac{\Lambda_{\mathrm{F}, t+1}^{1}}{\Lambda_{\mathrm{F}, t}^{1}} g_{\mathrm{Z} t}^{-\sigma_{c}} \frac{q_{\mathrm{F}, t+1}^{a}}{q_{\mathrm{F}, t}^{a}}\right] .
\end{gathered}
$$

Combining equations (B.4) and (B.5) and log-linearizing,

$$
E_{t}\left(\hat{\Lambda}_{\mathrm{F}, t+1}^{1}-\hat{\Lambda}_{\mathrm{F}, t}^{1}\right)-E_{t}\left(\hat{\Lambda}_{\mathrm{H}, t+1}^{1}-\hat{\Lambda}_{\mathrm{H}, t}^{1}\right)=E_{t}\left(\operatorname{rêr}_{t+1}-\operatorname{rêr}_{t}\right)-\frac{\psi_{1}}{\beta} \hat{d}_{\mathrm{H}, t},
$$

where $\hat{d}_{\mathrm{H}, t}=\frac{B_{\mathrm{H}, t}-B}{Z_{t-1}}$. Finally, the law of motion of bond holding is

$$
\beta \hat{d}_{\mathrm{H}, t}=\hat{d}_{\mathrm{H}, t-1}+\left(\operatorname{rer}_{t}+q_{\mathrm{F}, t}^{a}+a_{\mathrm{F}, t}-\left(q_{\mathrm{H}, t}^{b}+b_{\mathrm{H}, t}\right)-\operatorname{gdp}_{\mathrm{H}, t}\right) .
$$

\section{APPENDIX C: DATA DESCRIPTION}

I consider the United States as the home country and the rest of the world (ROW) as the foreign country. The ROW is made up of Canada, Japan, Australia, and 15 European countries (Austria, Belgium, Denmark, Finland, France, Germany, Greece, Ireland, Italy, Norway, the Netherlands, Portugal, Spain, Sweden, and the United Kingdom). The data series are quarterly and are taken from the OECD Main Economic Indicators (MEI). The sample spans from 1973:02 to 2007:04. Following Raffo (2009), GDP and GDP components for the ROW are aggregated by summing the OECD measure of VPVOBARSA (million of US\$, volume estimates, and fixed PPPs, at constant prices, s.a.a.r). The definition for the variables (all at constant prices) are as follows:

- GDP (U.S.): Gross domestic product

- Consumption (U.S.): Private plus government final consumption expenditure

- Investment (U.S.): Gross fixed capital formation

- GDP (ROW): Gross domestic product obtained from OECD Main Economic Indicators (MEI), aggregated over the ROW

- Consumption (ROW): Private plus government final consumption expenditure, aggregated over the ROW

- Investment (ROW): Gross fixed capital formation, aggregated over the ROW

- Real exchange rate: Trade-weighted measure of the real value of the U.S. dollar, indexed to March $1973=100$, as reported by the Board of Governors (Broad Index). The monthly data are converted to quarterly by taking averages over months in the quarter. 
- Terms of trade: Ratio of import prices (imports at current prices over imports at constant prices) to export prices (exports at current prices over exports at constant prices)

\section{APPENDIX D: MEASUREMENT EQUATIONS}

The demeaned vector of observables is

$$
Z_{t}=\left[\mathrm{dlGDP}_{\mathrm{H}, t}, \mathrm{dlGDP}_{\mathrm{F}, t}, \mathrm{dl} C_{\mathrm{H}, t}, \mathrm{dl}_{\mathrm{F}, t}, \mathrm{dl} I_{\mathrm{H}, t}, \mathrm{dl}_{\mathrm{F}, t}, 1 \mathrm{RER}_{t}, \mathrm{ITOT}_{t}\right]
$$

where 1 and $\mathrm{dl}$ stand for $\log$ and $\log$ difference, respectively. The corresponding loglinearized measurement equations, mapping the observables and transformed variables, are as follows:

$$
\left[\begin{array}{c}
\mathrm{dlGDP}_{\mathrm{H}, t} \\
\mathrm{dlGDP}_{\mathrm{F}, t} \\
\mathrm{dl} C_{\mathrm{H}, t} \\
\mathrm{dl} C_{\mathrm{F}, t} \\
\mathrm{dl} I_{\mathrm{H}, t} \\
\mathrm{dl}_{\mathrm{F}, t} \\
\operatorname{lRER}_{t} \\
\operatorname{lTOT}_{t}
\end{array}\right]=\left[\begin{array}{c}
\left(\mathrm{gdp}_{\mathrm{H}, t}-\mathrm{gd}_{\mathrm{H}, t-1}\right) \\
\left(\mathrm{gdp}_{\mathrm{F}, t}-\mathrm{gdp}_{\mathrm{F}, t-1}\right) \\
\left(\hat{c}_{\mathrm{H}, t}-\hat{c}_{\mathrm{H}, t-1}\right) \\
\left(\hat{c}_{\mathrm{F}, t}-\hat{c}_{\mathrm{F}, t-1}\right) \\
\left(\hat{i}_{\mathrm{H}, t}-\hat{i}_{\mathrm{H}, t-1}\right) \\
\left(\hat{i}_{\mathrm{F}, t}-\hat{i}_{\mathrm{F}, t-1}\right) \\
\operatorname{rê}_{t} \\
\operatorname{tot}_{t}
\end{array}\right]+\left[\begin{array}{c}
\hat{g}_{Z t-1} \\
\hat{g}_{Z t-1} \\
\hat{g}_{Z t-1} \\
\hat{g}_{Z t-1} \\
\hat{g}_{Z t-1} \\
\hat{g}_{Z t-1} \\
0 \\
0
\end{array}\right] .
$$

\section{APPENDIX E: COINTEGRATED SHOCKS}

\section{E.1. ESTIMATION AND RESULTS}

In my benchmark specification, I do not discipline the behavior of IST shocks by including observations on the relative price of investment. In this section, I compare and contrast my findings with Mandelman et al. (2011). To this end, I perform two experiments. First, I replicate the findings in Mandelman et al. (2011) using my full information approach. I reestimate my model under the assumption that both IST and TFP shocks have unit roots and are cointegrated, whereas preference shocks are stationary and country-specific. In addition, I include the observation of the relative prices of investment as empirical counterparts of IST shocks. I obtained the relative price series from Mandelman et al. (2011), the sample period for which spans from 1983:02 to 2007:04. This series is based on investment deflator series that are not quality-adjusted and are easily available for OECD countries. I replace the investment quantities used previously to identify the "combined" IST shocks by relative 
TABLE E.1. Posterior means of the model's parameters

\begin{tabular}{lcc}
\hline Parameter & Coint. INCP & Coint. EXCP \\
\hline$(\tau-1)$ & 0.99 & 0.98 \\
$\theta$ & 1.51 & 0.85 \\
$\phi$ & 0.19 & 10.15 \\
$\alpha$ & 0.25 & 0.34 \\
$\rho_{1}^{a}$ & - & - \\
$\rho_{2}^{a}$ & - & - \\
$\rho_{1}^{v}$ & - & - \\
$\rho_{2}^{v}$ & - & - \\
$\rho_{1}^{g}$ & 0.91 & 0.87 \\
$\rho_{2}^{g}$ & 0.91 & 0.61 \\
$\sigma_{1}^{z}($ in \%) & 0.29 & 0.30 \\
$\sigma_{2}^{z}$ (in \%) & 0.19 & 0.20 \\
$\sigma_{1}^{v}$ (in \%) & 0.51 & 2.64 \\
$\sigma_{2}^{v}$ (in \%) & 0.52 & 3.81 \\
$\sigma_{1}^{g}$ (in \%) & 2.46 & 3.33 \\
$\sigma_{2}^{g}$ (in \%) & 1.71 & 3.80 \\
$\operatorname{ppp}_{1}($ in \%) & 9.40 & 6.94 \\
$\operatorname{ppp}_{2}($ in \%) & 3.20 & 8.70 \\
Log marginal likelihood & -1229.186 & -2125.572 \\
\hline
\end{tabular}

Notes: "Coint. EXCP" and the benchmark specifications are estimated using the same observables, and thus are comparable. The model "Coint. INCP" has different observables than the benchmark. Consequently, its explanatory power cannot be compared with that of the benchmark.

prices. My new vector of observables is

$$
Z_{t}=\left[\mathrm{dlGDP}_{\mathrm{H}, t}, \mathrm{dlGDP}_{\mathrm{F}, t}, \mathrm{dl}_{\mathrm{H}, t}, \mathrm{dl}_{\mathrm{F}, t}, \operatorname{lRER}_{t}, \operatorname{lTOT}_{t}, \mathrm{dl}_{\mathrm{H}, t}, \mathrm{dl} v_{\mathrm{F}, t}\right] .
$$

I impose cointegration restrictions from Mandelman et al. (2011) and include measurement errors in the measurement equations of the real exchange rate and terms of trade. The experiment results are given under the heading 'Coint. INCP.' First, Table E.1 suggests that the estimated standard deviations of IST shocks drop substantially compared with the benchmark, confirming the findings of Mandelman et al. (2011). This is not surprising, because the volatilities of the relative-price-of-investment series that are the empirical counterparts of IST shocks are 0.49 and 0.52 of the home and foreign country, respectively. Second, the variance decomposition exercise in Table E. 2 shows that the IST shocks fail to make a substantial model-based contribution to the variances of quantities and international relative prices. Finally, Table E. 3 confirms that this model specification cannot account for the real exchange rate puzzle and terms of trade puzzle. The high volatilities in the two relative prices are due to the nonstructural measurement errors, which are not contained in the primitive of the model.

In my second experiment, I reestimate the model in the first experiment, but exclude the observations on the relative price of the investment (header "Coint. EXCP"). The set of observables and the sample size are the same as my benchmark specification. The purpose 
TABLE E.2. Variance decomposition in "Coint. INCP" model

\begin{tabular}{|c|c|c|c|c|c|c|c|c|}
\hline \multirow[b]{2}{*}{ Percent variance } & \multicolumn{3}{|c|}{ United States } & \multicolumn{3}{|c|}{ ROW } & \multirow[b]{2}{*}{ rer } & \multirow[b]{2}{*}{ tot } \\
\hline & $\Delta y_{1}$ & $\Delta c_{1}$ & $\Delta i_{1}$ & $\Delta y_{2}$ & $\Delta c_{2}$ & $\Delta i_{2}$ & & \\
\hline $\begin{array}{l}\text { Home neutral } \\
\text { tech. shocks }\end{array}$ & 90.73 & 27.57 & 18.1 & 1.27 & 6.73 & 48.52 & 0.43 & 5.79 \\
\hline $\begin{array}{c}\text { Foreign neutral } \\
\text { tech. shocks }\end{array}$ & 0.26 & 1.56 & 21.82 & 82.9 & 21.9 & 7.42 & 0.19 & 2.48 \\
\hline $\begin{array}{l}\text { Home IST } \\
\text { shocks }\end{array}$ & 4.66 & 1.51 & 5.34 & 0.2 & 0.8 & 8.68 & 0.3 & 4 \\
\hline $\begin{array}{c}\text { Foreign IST } \\
\text { shocks }\end{array}$ & 0.12 & 0.54 & 9.72 & 10.7 & 3 & 5.56 & 0.32 & 4.32 \\
\hline $\begin{array}{l}\text { Home prefer- } \\
\text { ence shocks }\end{array}$ & 4.08 & 66.96 & 39.08 & 0.68 & 7.01 & 11.58 & 0.44 & 5.93 \\
\hline $\begin{array}{c}\text { Foreign prefer- } \\
\text { ence shocks }\end{array}$ & 0.16 & 1.85 & 5.93 & 4.24 & 60.56 & 18.24 & 0.22 & 2.9 \\
\hline $\mathrm{PPP}_{1}$ shock & 0 & 0 & 0 & 0 & 0 & 0 & 98.1 & 0 \\
\hline $\mathrm{PPP}_{2}$ shock & 0 & 0 & 0 & 0 & 0 & 0 & 0 & 74.59 \\
\hline
\end{tabular}

Notes: The table reports the forecast error variance decomposition at infinite horizon. Each entry gives the percent contribution of each shock to fluctuations in each variable. The $\mathrm{PPP}_{1}, \mathrm{PPP}_{2}$ shocks are the measurement errors included in the measurement equations of the real exchange rate and terms of trade respectively.

TABLE E.3. Second moments, volatilities, and correlations

\begin{tabular}{|c|c|c|c|c|c|c|c|c|}
\hline \multirow[b]{3}{*}{ Std. dev.(in \%) } & \multicolumn{7}{|c|}{ Panel A } & \multirow[b]{3}{*}{ tot } \\
\hline & \multicolumn{3}{|c|}{ United States } & \multicolumn{3}{|c|}{ ROW } & \multirow[b]{2}{*}{ rer } & \\
\hline & $\Delta \mathrm{gdp}_{1}$ & $\Delta c_{1}$ & $\Delta i_{1}$ & $\Delta \operatorname{gdp}_{2}$ & $\Delta c_{2}$ & $\Delta i_{2}$ & & \\
\hline Data & 0.80 & 0.51 & 2.05 & 0.44 & 0.37 & 1.13 & 9.01 & 6.61 \\
\hline Coint. INCP & 0.59 & 0.78 & 1.67 & 0.34 & 0.47 & 1.96 & 9.54 & 3.97 \\
\hline Coint. EXCP & \multicolumn{7}{|c|}{ Panel B } & 11.77 \\
\hline Other correlations & $\begin{array}{c}\text { rer, } \\
c_{1}-c_{2}\end{array}$ & $\begin{array}{l}\text { tot, } \\
\operatorname{gdp}_{1}\end{array}$ & $\operatorname{gdp}_{2}$ & $\begin{array}{l}\operatorname{gdp}_{1} \\
\operatorname{gdp}_{2}\end{array}$ & $\begin{array}{l}c_{1}, \\
c_{2}\end{array}$ & $\begin{array}{c}i_{1}, \\
i_{2}\end{array}$ & & \\
\hline Data & -0.20 & -0.29 & & 0.57 & 0.34 & 0.41 & & \\
\hline Coint. INCP & 0.10 & 0.24 & & 0.07 & -0.18 & -0.07 & & \\
\hline Coint. EXCP & 0.24 & 0.26 & & 0.34 & 0.41 & -0.02 & & \\
\hline
\end{tabular}

of this exercise is to compare and contrast the model's fit with my benchmark model. The results indicate the following. First, Table E.1 indicates that the estimated standard deviations of IST shocks are much larger (around 2.64 and 3.81) than under "Coint. INCP." Consequently, the estimates of the investment adjustment costs parameter are also much higher (around 10.15), to dampen the responses of investment. Second, Table E. 3 shows that 
despite high volatilities in IST shocks, this model cannot resolve the correlation puzzles, primarily because of high adjustment costs. ${ }^{31}$ Finally, Table E. 1 gives the log marginal likelihood under this specification. It is clear that the overall fit of the benchmark model is far better than this alternative model specification (-717.689 vs. $-2,125.572)$. It may be suggested that this is because whereas the model "Coint. EXCP" only takes into account a specific source of the variation in investment, my benchmark specification allows for all sources of unexplained variations in both investment and productive capital and hence can match the observables better. Therefore, the underlying assumption of stationary IST shock processes not only is crucial for the results to hold but also has strong support from the data.

\section{E.2. LOG-LINEARIZED MODEL UNDER COINTEGRATED SHOCKS}

Following Mandelman et al. (2011), I assume that the country-specific TFP and IST shocks are unit root nonstationary and are cointegrated across countries. Define $Z_{i t-1}=$ $A_{i t-1}^{1 /(1-\alpha)} V_{i t-1}^{\alpha /(1-\alpha)}$, where $i=\mathrm{H}, \mathrm{F}$. To make my model stationary, I rescale the variables so that $c_{i t}=\frac{C_{i t}}{Z_{i t-1}}, i_{t}=\frac{I_{i t}}{Z_{i t-1}}, k_{i t-1}=\frac{K_{i t-1}}{Z_{i t-1} V_{i t-1}}, r_{i t}=R_{i t} V_{i t-1}, w_{i t}=\frac{W_{i t}}{Z_{i t-1}}, \Lambda_{i t}^{1}=\lambda_{i t}^{1} Z_{i t-1}^{\sigma_{c}}$, and $\Lambda_{i t}^{2}=\lambda_{i t}^{2} Z_{i t-1}^{\sigma_{c}} V_{i t-1}$. Also, I define $g_{Z i t}=\frac{Z_{i t}}{Z_{i t-1}}, g_{V i t}=\frac{V_{i t}}{V_{i t-1}}$, and $g_{A i t}=\frac{A_{i t}}{A_{i t-1}}, d Z_{t}=$ $\frac{Z_{\mathrm{H}, t}}{Z_{\mathrm{F}, t}}, d V_{t}=\frac{V_{\mathrm{H}, t}}{V_{\mathrm{F}, t}}, d A_{t}=\frac{A_{\mathrm{H}, t}}{A_{\mathrm{F}, t}}$. Then the detrended log-linearized equations are as follows:

- Consumption Euler equations:

$$
\begin{aligned}
& \frac{1}{\left(\bar{c}-\psi \bar{l}^{\tau}\right)^{\sigma_{c}}}\left[\bar{c} \hat{c}_{\mathrm{H}, t}-\psi \tau \bar{l}^{\tau} \hat{l}_{\mathrm{H}, t}\right]=-\frac{1}{\sigma_{c}}\left[\hat{\Lambda}_{\mathrm{H}, t}^{1}-\hat{g}_{\mathrm{H}, t}\right], \\
& \frac{1}{\left(\bar{c}-\psi \bar{l}^{\tau}\right)^{\sigma_{c}}}\left[\bar{c} \hat{c}_{\mathrm{F}, t}-\psi \tau \bar{l}^{\tau} \hat{l}_{\mathrm{F}, t}\right]=-\frac{1}{\sigma_{c}}\left[\hat{\Lambda}_{\mathrm{F}, t}^{1}-\hat{g}_{\mathrm{F}, t}\right] .
\end{aligned}
$$

- Labor supply:

$$
\begin{aligned}
& (\tau-1) \hat{l}_{\mathrm{H}, t}=\hat{w}_{\mathrm{H}, t}+\hat{q}_{\mathrm{H}, t}^{a}, \\
& (\tau-1) \hat{l}_{\mathrm{F}, t}=\hat{w}_{\mathrm{F}, t}+\hat{q}_{\mathrm{F}, t}^{b} .
\end{aligned}
$$

- Capital Euler equations:

$$
\begin{aligned}
& \hat{\Lambda}_{\mathrm{H}, t}^{2}=\frac{\beta}{g_{Z}^{\sigma_{c}} g_{v}} E_{t}\left[(1-\delta) \hat{\Lambda}_{\mathrm{H}, t+1}^{2}+\left(\frac{g_{Z}^{\sigma_{c}} g_{v}}{\beta}-1+\delta\right)\left(\hat{\Lambda}_{\mathrm{H}, t+1}^{1}+\hat{r}_{\mathrm{H}, t+1}+\hat{q}_{\mathrm{H}, t+1}^{a}\right)\right] \\
& -\sigma_{c} \hat{g}_{Z, \mathrm{H}, t}-\hat{g}_{V, \mathrm{H}, t}, \\
& \hat{\Lambda}_{\mathrm{F}, t}^{2}=\frac{\beta}{g_{Z}^{\sigma_{c}} g_{v}} E_{t}\left[(1-\delta) \hat{\Lambda}_{\mathrm{F}, t+1}^{2}+\left(\frac{g_{Z}^{\sigma_{c}} g_{v}}{\beta}-1+\delta\right)\left(\hat{\Lambda}_{\mathrm{F}, t+1}^{1}+\hat{r}_{\mathrm{F}, t+1}+\hat{q}_{\mathrm{F}, t+1}^{b}\right)\right] \\
& \quad-\sigma_{c} \hat{g}_{Z, \mathrm{~F}, t}-\hat{g}_{V, \mathrm{~F}, t} .
\end{aligned}
$$

- Investment Euler equations:

$$
\begin{aligned}
& \Lambda_{\mathrm{H}, t}^{1}=\Lambda_{\mathrm{H}, t}^{2}+\hat{g}_{V, \mathrm{H}, t}-\phi g_{z} g_{v}\left(\hat{i}_{\mathrm{H}, t}-\hat{i}_{\mathrm{H}, t-1}+\hat{g}_{V, \mathrm{H}, t}+\hat{g}_{Z, \mathrm{H}, t-1}\right) \\
& \quad+\beta \phi g_{z}^{2-\sigma_{c}} g_{v}^{2} E_{t}\left(\hat{i}_{\mathrm{H}, t+1}-\hat{i}_{\mathrm{H}, t}+\hat{g}_{V, \mathrm{H}, t+1}+\hat{g}_{Z, \mathrm{H}, t}\right)
\end{aligned}
$$




$$
\begin{aligned}
& \Lambda_{\mathrm{F}, t}^{1}=\Lambda_{\mathrm{F}, t}^{2}+\hat{g}_{V, \mathrm{~F}, t}-\phi g_{z} g_{v}\left(\hat{i}_{\mathrm{F}, t}-\hat{i}_{\mathrm{F}, t-1}+\hat{g}_{V, \mathrm{~F}, t}+\hat{g}_{Z, \mathrm{~F}, t-1}\right) \\
& \quad+\beta \phi g_{z}^{2-\sigma_{c}} g_{v}^{2} E_{t}\left(\hat{i}_{\mathrm{F}, t+1}-\hat{i}_{\mathrm{F}, t}+\hat{g}_{V, \mathrm{~F}, t+1}+\hat{g}_{Z, F, t}\right) .
\end{aligned}
$$

- Capital utilization Euler equations:

$$
\begin{gathered}
\hat{\Lambda}_{\mathrm{H}, t}^{1}+\hat{r}_{\mathrm{H}, t}+\hat{q}_{\mathrm{H}, t}^{a}=\hat{\Lambda}_{\mathrm{H}, t}^{2}+\sigma_{u} \hat{h}_{\mathrm{H}, t}, \\
\hat{\Lambda}_{\mathrm{F}, t}^{1}+\hat{r}_{\mathrm{F}, t}+\hat{q}_{\mathrm{F}, t}^{b}=\hat{\Lambda}_{\mathrm{F}, t}^{2}+\sigma_{u} \hat{h}_{\mathrm{F}, t} .
\end{gathered}
$$

- Capital accumulation equations:

$$
\begin{aligned}
\hat{k}_{\mathrm{H}, t} & =\frac{(1-\delta)}{g_{Z} g_{V}}\left(\hat{k}_{\mathrm{H}, t-1}-\hat{g}_{Z, \mathrm{H}, t}-\hat{g}_{V, \mathrm{H}, t}\right)-\frac{\kappa}{g_{Z} g_{V}} \bar{h}^{\left(\sigma_{u}+1\right)} \hat{h}_{\mathrm{H}, t} \\
+ & \left(1-\frac{(1-\delta)}{g_{Z} g_{V}}\right)\left(\hat{i}_{\mathrm{H}, t}-\hat{g}_{Z, \mathrm{H}, t}\right), \\
\hat{k}_{\mathrm{F}, t} & =\frac{(1-\delta)}{g_{Z} g_{V}}\left(\hat{k}_{\mathrm{F}, t-1}-\hat{g}_{Z, \mathrm{~F}, t}-\hat{g}_{V, \mathrm{~F}, t}\right)-\frac{\kappa}{g_{Z} g_{V}} \bar{h}^{\left(\sigma_{u}+1\right)} \hat{h}_{\mathrm{F}, t} \\
& +\left(1-\frac{(1-\delta)}{g_{Z} g_{V}}\right)\left(\hat{i}_{\mathrm{F}, t}-\hat{g}_{Z, \mathrm{~F}, t}\right) .
\end{aligned}
$$

- Labor demand:

$$
\begin{gathered}
\hat{w}_{\mathrm{H}, t}=\hat{g}_{A, \mathrm{H}, t}+\alpha\left(\hat{k}_{\mathrm{H}, t-1}+\hat{h}_{\mathrm{H}, t}\right)-\alpha \hat{l}_{\mathrm{H}, t}, \\
\hat{w}_{\mathrm{F}, t}=\hat{g}_{A, \mathrm{~F}, t}+\alpha\left(\hat{k}_{\mathrm{F}, t-1}+\hat{h}_{\mathrm{F}, t}\right)-\alpha \hat{l}_{\mathrm{F}, t} .
\end{gathered}
$$

- Capital demand:

$$
\begin{gathered}
\hat{r}_{\mathrm{H}, t}=\hat{g}_{A, \mathrm{H}, t}+(\alpha-1)\left(\hat{k}_{\mathrm{H}, t-1}+\hat{h}_{\mathrm{H}, t}\right)+(1-\alpha) \hat{l}_{\mathrm{H}, t}, \\
\hat{r}_{\mathrm{F}, t}=\hat{g}_{A, \mathrm{~F}, t}+(\alpha-1)\left(\hat{k}_{\mathrm{F}, t-1}+\hat{h}_{\mathrm{F}, t}\right)+(1-\alpha) \hat{l}_{\mathrm{F}, t} .
\end{gathered}
$$

- Demand for intermediate goods:

$$
\begin{gathered}
\hat{a}_{\mathrm{H}, t}=\hat{G}_{\mathrm{H}, t}-\theta \hat{q}_{\mathrm{H}, t}^{a}, \\
\hat{b}_{\mathrm{H}, t}=\hat{G}_{\mathrm{H}, t}-\theta \hat{q}_{\mathrm{H}, t}^{b}+d Z_{t-1}, \\
\hat{a}_{\mathrm{F}, t}=\hat{G}_{\mathrm{F}, t}-\theta \hat{q}_{\mathrm{F}, t}^{a}-d Z_{t-1}, \\
\hat{b}_{\mathrm{F}, t}=\hat{G}_{\mathrm{F}, t}-\theta \hat{q}_{\mathrm{F}, t}^{b} .
\end{gathered}
$$

- Production functions:

$$
\begin{gathered}
\hat{G}_{\mathrm{H}, t}=\omega \hat{a}_{\mathrm{H}, t}+(1-\omega)\left(\hat{b}_{\mathrm{H}, t}-d Z_{t-1}\right), \\
\hat{G}_{\mathrm{F}, t}=\omega \hat{b}_{\mathrm{F}, t}+(1-\omega)\left(\hat{a}_{\mathrm{F}, t}+d Z_{t-1}\right) . \\
g \hat{d} p_{H, t}=\hat{g}_{A, H, t}+(\alpha)\left(\hat{k}_{H, t-1}+\hat{h}_{H, t}\right)+(1-\alpha) \hat{l}_{H, t} \\
g \hat{d} p_{F, t}=\hat{g}_{A, F, t}+(\alpha)\left(\hat{k}_{F, t-1}+\hat{h}_{F, t}\right)+(1-\alpha) \hat{l}_{F, t}
\end{gathered}
$$


- Market clearing:

$$
\begin{aligned}
g \hat{d} p_{\mathrm{H}, t} & =\omega \hat{a}_{\mathrm{H}, t}+(1-\omega) \hat{a}_{\mathrm{F}, t}, \\
g \hat{d} p_{F, t} & =\omega \hat{b}_{\mathrm{F}, t}+(1-\omega) \hat{b}_{\mathrm{H}, t}, \\
\hat{G}_{\mathrm{H}, t} & =\frac{\bar{c}}{\mathrm{~g} \overline{\mathrm{d} p}} \hat{c}_{\mathrm{H}, t}+\frac{\bar{c}}{\mathrm{~g} \overline{\mathrm{d} p}} \hat{i}_{\mathrm{H}, t}, \\
\hat{G}_{\mathrm{F}, t} & =\frac{\bar{c}}{\mathrm{~g} \overline{\mathrm{d} p}} \hat{c}_{\mathrm{F}, t}+\frac{\bar{c}}{\mathrm{~g} \overline{\mathrm{d} p}} \hat{i}_{\mathrm{F}, t} .
\end{aligned}
$$

- Law of one price:

$$
\begin{aligned}
& \hat{q}_{\mathrm{H}, t}^{a}=\operatorname{rêr}_{t}+\hat{q}_{\mathrm{F}, t}^{a}, \\
& \hat{q}_{\mathrm{H}, t}^{b}=\operatorname{rêr}_{t}+\hat{q}_{\mathrm{F}, t}^{b} .
\end{aligned}
$$

- Shock processes:

Cointegrated technology shocks:

$$
\begin{aligned}
& {\left[\begin{array}{c}
\Delta \log \left(X_{\mathrm{H}, t}\right) \\
\Delta \log \left(X_{\mathrm{F}, t}\right)
\end{array}\right]=\left[\begin{array}{c}
c_{\mathrm{H}, X} \\
c_{\mathrm{F}, X}
\end{array}\right]+\left[\begin{array}{c}
\delta_{\mathrm{H}, X} \\
\delta_{\mathrm{F}, X}
\end{array}\right]\left[\log \left(X_{\mathrm{H}, t-1}\right)-\eta_{X} \log \left(X_{\mathrm{F}, t-1}\right)-\log \left(\zeta_{X}\right)\right]} \\
& \quad+\left[\begin{array}{c}
\epsilon_{\mathrm{H}, t}^{X} \\
\epsilon_{\mathrm{F}, t}^{X}
\end{array}\right]
\end{aligned}
$$

where $X=A, V$. $\left(1,-\eta_{X}\right)^{\prime}$ is the cointegrating vector, $c_{\mathrm{H}, X}, c_{\mathrm{F}, X}$ are intercept terms, $\delta_{\mathrm{H}, X}, \delta_{\mathrm{F}, X}$ are speeds of adjustment, and $\zeta_{X}$ is the constant in the cointegration equation.

Stationary preference shock:

$$
\hat{g}_{i t}=\rho_{i}^{g} \hat{g}_{i t-1}+\epsilon_{i t}^{g} \text {. }
$$

